\title{
The Early Phase of Spark Ignition
}

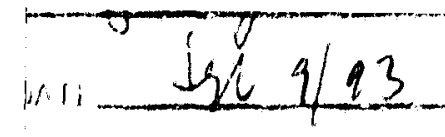

by

Phillp Lawrence Pitt

A Dissertation Submitted in Partial Fulfiliment of the Requirements for the Degree of

DOCTOR OF PHILOSOPHY

In the Department of Physics and Astronomy

We accept this thesis as conforming to the required standard

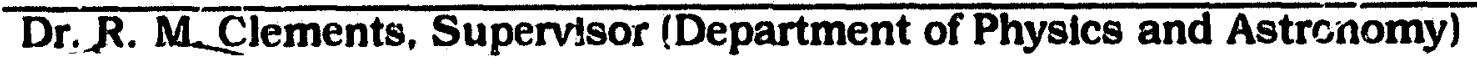

C( Dr. M Mewey, Deprentmental Mernber (Department of Physics and Astronomy)

Dr. J.T. Weaver, Departmental Member (Department of Physics and Astronomy)

Dr. T. Dingle, Outsdd Member (Department of Chemistry)

Dr. D. R. Topham. Cutside Member (Department of Mechanical Enghecring)

Dr.A. K. Oppenhelm, External Examıner (Unlversity of California, Berkeley)

(1) PHILIP LAWRENCE PITT, 1993

University of Victoria

All rights reserved. Dissertation may not be reproduced in whole or in part. hy photocopying or other means, without the permission of the author. 
Supervisor: Professor R.M.Clements

\section{ABSTRACT}

In this dissertation, some practical Ignition techniques are presented that show how some problems of lean-burn combustion can be overcome. Then, to shed light on the effects of the Ignition techniques described. the focus shifts to the niore specific problem of the early phase of spark Ignition. Thermal models of ignition are reviewed These models treat the energy prov!ded by the electrical discharge as a point scrurce, delivered Infinitely fast and creating a spherically symmetric Ignition kernel. The thesis challenges the basls of these thermal models by reviewing the work of man; investigators who have clearly shown that the temporal characteristics of the discharge have a profound effect upon ignition. Photographlc evidence of the early phase of Ignition, as well as other evidence from the literature, is also presented. The evidence clearly demonstrates that the morphology of spark kernels in the early phase of development is toroidal, not spherical as suggested by thermal models. A new perspective for ignition, a fluid dynamic point of view, is described. The conmon Ignition devices are then classifed according to fluid dynamics. A model descitbing the behaviour of spark kernels is presented, which extends a previously established mixing model for plasma jets, to the reaim of conventional axial discharges. Comparison of the model behaviour to some limited data is made. The model is modified by including the effect of heat addition from combustion, and Ignition criterla are discussed.

\footnotetext{
Dr. R. M. Clements, Supervisor (Departmerit of Physics and Astronomy)
}
Dr:S. M. Dewoy. Departmental Member (Department of Physics and Astronomy)
Dr. $\sqrt{3}$. Weaver, Departmental Member (Department of Physics and Astrong(hy)

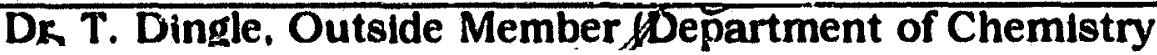
Dr. D. R. Topham, Outslce Member (Department of Mechanical Engineering) Dr. A. K. Oppenheim, External Examiner (University of Californla, 
Tabic of Contents

Abstract II

Table of Contents III

List of Tables IV

List of Figures $v$

Acknowledgements vi

Dedication vil

Chapter 1 Introduction 1

Chapter 2 Practical Ignition Techniques for Lean-Burn or 15 Alternative Fueled Engines

Chapter 3 The Thermal Approach to Spark Ignition 29

Chapter 4 Spark Kernel Dynamics and Morphology 41

Chapter 5 A Unifled Approach to Spark Kery :1 53

Development: Mixing Models

Chapter 6 A Unified Approach to Spark Kernel

Development: Combustible Mixtures

Chapter 7 Summary $\quad 84$

Literature cited $\quad 89$

Appendux I Relavent papers published by the author 92

Arpendix Il Non-combusting model solutions 93

Appenclix III Constant density modei solutions 97 


\section{List of Tables}

Table 5.1 Ignition sources and their model behaviour

53

Table 5.2 Classifaction of Ignition sources

60

Table 5.3 Scallng quantitles

65

Table 5.4 Scalling data

71 


\section{List oi Figuras}

Figure 1.1 Ideal and real engine cysles 5

Figure 1.2 Distribution of engine energy 6

Figure 1.3 Otto cycle effictency

Figure 1.4 Cylinder pressure with normal combustion and knock 8

Figure 2.1 Simple closed combustion system 15

Figure 2.2 Pressure trace from simple combustion system 16

Figure 2.3 Pressure-time histories as the mixture becomes increasingly leater 17

Figure 2.4 Effect of changling fuel from propane to methane 18

Figure 2.5 Schematic of puff Jet system 21

Figure 2.6 Pressure-time histortes for puff jet, plasma jet and spark ignittun 22

Figure $2.7 \mathrm{Log} p V^{\psi}$ vs crank angle for $\lambda=1.0 \quad 26$

Figure 2.8 Average presisure waveforms as a function of normailzed alr:fuel ratto 27

Figure 3.1 Mallard-LCChateller descriptirn of a laminar flame temperature profle 32

Flgure 4.1 Discharge curient and voltage charactertstics 44

Figure 4.2 Temperature proflie of a spark kernel, after Maly and Vogel (197B) 46

Figure 4.3 Schlleren tmages of a spark discherge, along the ilscharge axts 51

Figure 4.4 S.shiteren inages of spark discharge, normal to the discharge axts $\quad 52$

Figure 4.5 Shadowgraph images of spark kernels $\quad 52$

Figure 5.1 Bastc thermal model features and experimental observations 56

Figure 5.2 Basic igniter types $\quad 57$

Figure 5.3 Toroldal coordinate system 63

Figure 5.4a. Non-combusting model; equation 5.14 67

Figure 5.4b. Non-cornbusting model; equation $5.15 \quad 67$

Figure 5.4c. Non-combusting model; equation $5.16 \quad 68$

Figure 5.5a. Example 1 data $\left({ }^{\circ}\right)$ and the non-comburting inodel; equation 5.1470

Figure 5.5b. Example 1 data (*) and the non-combusting, inodel; equation 5.1670

Figure 5.6. Example: 2 data (") and the non-combusting model; equation 5.1471 


\section{Acknowledgments}

I would like to convey my appreciation to the many people who helped me during my tIme with the Plasma Physics Laboratory at UVIc. First and foremost. I would like to thank my supervisor. Dr. Monty Clements, whose persistent "encouragement", even when he thought I no longer exdsted, is the reason this dissertation was completed. Dr. David Topham provided many stimulating aiscussions and ideas. many of which have become entwined in this thesis, through the pertod of our collaboration. Through a generous loan of time on a Spln Physlcs camera at the University of Alberta. Dr. Peter Smy provided me, along with some fatherly advice, the opportunity to obtain some key experimental evidence which appears in this work. I also had the pleasure of working with many people in the lab who contributed to my work in several valuable ways. People like David Ridley, Russ Warren. Dr. Bob Smith, Gary Schefler, Dave, Smith. Peter Ward and Dr. Paul Fischer are great colleagues and friends. Finally. I would like to thank my editor, Georgina Montgomery, who showed no mercy in knifing her way through my obfuscation, cven thouglı she marrted me. 


\section{Dedication}

For my friher. Phillp Donald Pitt, on the oscasion of his seventy-nfth birthday, June 14, 1995. 
A llttle Inaccuracy someidmes saves tons of explanation-H.H. Munro (Sak?)

\section{Introduction}

\subsection{Environmental Impact on Conibustion Engine Design}

Combustion has been used by humans as a source of e. ergy for a long time. It was Prometheus who, it is claimed, stole fire from the gods and gave it to Earth's more common Inhabitants. Unfortunately, for his efforts Prometheus wound up chialned to a rock where he was lashed by the sea and burned by a relentless sun. Perhaps Prometheus' ultimate fate foretold of dire consequences should humans misuse fire. We have. Are we and future generations to wind up chalned to a decaying economic and social system and lashed by shifing climatic change, only to be burned in a global greenhouse? Thank you. Prometheus.

There is growing awareness of the environmental effects of energy use by soctety. Consequently, there is an increasing demand to design systems that use energy more efficiently and, at the same time, render the byproducts of energy use more environmentally benign. To help society realize these new system design goals, details of the basic physical processes involved in energy use need to be understood. It is ore such detall that is examined in this thesis. 
In 1988, varjous estimates placed the global demand for energy near 318 exajoules (one exajoule $=10^{18}$ joiles). Of this amount. $88 \%$ was satisfed by the combustion of coal, oll or gas. Essentlally an oxidation reaction. combustion is of prastical interest only because of its exothermicity (Oppenhelm i985). The internal combustion (IC) engine is a fimuliar application of combustion. Usi + primarlly for transportation, the IC engine consumes one out of three barrels of oll and contributes $15 \%$ of the carbon dioxide emtssions in North America. In a typical year. IC engines in North America produce more than $10^{16}$ plston combustion evenits, each of which lasts approximately $10 \mathrm{msec}$ and releases aboit 1 $\mathrm{kJ}$ of energy. Even modest improvements In our understanding of the single pistor: combustion event may lead to improvements of efficlency that are measurable when multiplied so many times. Understanding the energy use detalls of the IC engine is thus very important in the context of eniergy systems and their environmental impact.

This thesis will examine the Initiation process of combustion, more commonly known as ignition, in spark-ignited IC engines. At the time the work reported in this thesis was begun (late 1983), a senior executive of the General Motors Research Laboratory (Agnew 1984) stated, "If there Is a need today for sclentific contributions to practical spark Ignition. it is Ir. the area of the flame initiation perfod...." Engline designers recognized that a complete understanding of the spark-Ignitton process was necessary if significant improvements in the efficlency and performance of spark-Ignited (SI) engines were to be realized. 
Ignition, at first glance, appears to be an "old" subject, well addressed in the literature and not worthy of further investigation by a late-twentieth century apprentice scientlst hoping to gain acceptance in the establishcd sclentific community. Surprisingly. however, the subject is still vigorously pursued, spurred recently by engine research. It must be remembered, nevertheless, that Ignition of combustible mixtures is a funclamental problem in combustion sclence and its relevance goes beyond ig:aition in engines to include safety issues 'nvolving the storage of flamınable or explosive substances.

\subsection{Improvements is Engine Performance: Avenues for the Engine Designer}

Present-day IC engine Ignition systems have evolved over inany years through a trial-and-error form of engineering. Because normal operating conditions for IC erigines remained conetant for nearly half a century, the spark-ignit!on systems that had bsen developed seemed to perform adlequately. However, once operating conditions necessary for high energy efficlency and lower emissions were explored. Ignition problems arose. Examples of these new IC operating, conditions include: states of very lean operation; high levels of exhaust gas recirculating; stratifled charge mixtures; highly turbulent mixtures; and use of fuels other than gasoline.

The motivation for some of these new operating conditions romes from environmental pressure to produce more efficient engines that meet more demanding emission standards. For example, lean mixtures piodure 
raluch lower CO and NO emisslois than do the normal stolchlometric mixtures prevalent for so nany years Also, the ratio of specific heats increases for lean mixturee, causing ar. l: icrease In the thermodynarnic efficlency of the combustion process. Whth Increasing learness. however. the flame propagation spted begins to degrade to the polnt whiere some of the fuel-air mixture falls to be consumed before the exhaust valve opens. This causes loss of output power and increased hydrocarbon emisstons. Highly turbulent combustion chambers have been developed to augrnent the flame speed and to help offset the problems of lean-burn combustion. Cleaner burning alternative fuels, such as methane (nat:iral gas), also Introduce similar combustion problems wheri used with existing engine technology.

For one to understand better the problem faced by the IC englne designer. It is useful to review the thermodynamic cycle of the IC - ne. Figure 1. i shows the classic Ideal "Otto" cycle. Superimposed is a real engine cycle, which shows the departure from the idcal case. A reul engine cycle suffers irom several loss mechanisms: pumping losses, timirig losses, heat transfer losses and friction losses. 


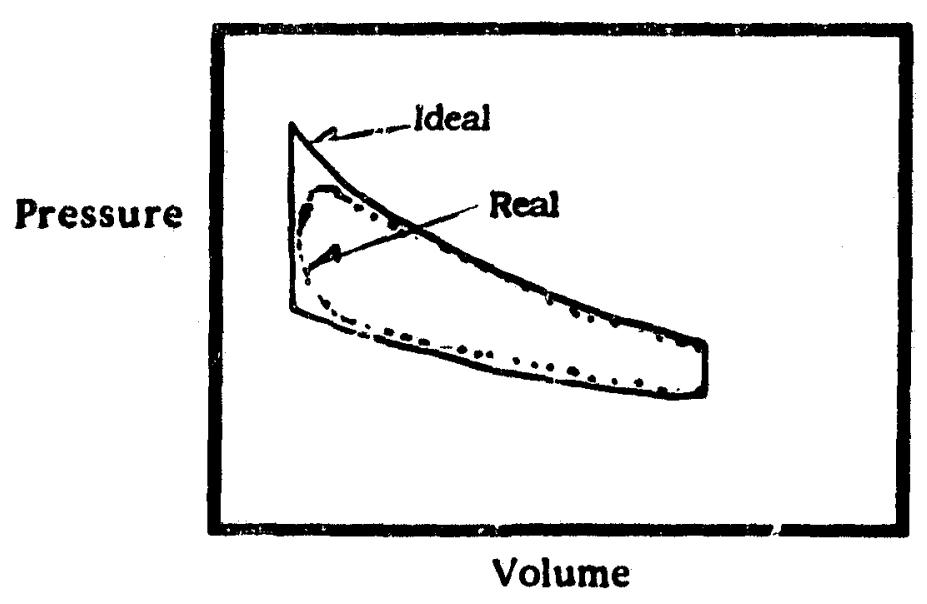

Figure 1.1 Ideal and real engine cycles.

Figure 1.2 Indicates the approximate distribution of the chemical energy avallable to an engine under dynamic (equivalent "road") condittons. The dynamic efficiency (work output) of $16 \%$ improves to about $30 \%$ for steady-state operation of the same engine. An engine providing mottve power to a road vehicle also has to overcome aerodynamic drag. transmission coupling losses, and dynamic friction. Further reduction of drag does not appear to be feasible, as most designs are nearing basic IImits and vehicle weight reduction is limited by safety considerations. Therefore, design attention is now focusing on inprovements in the real efficlency of engines. What can an engine designer do to improve engine effictency? 


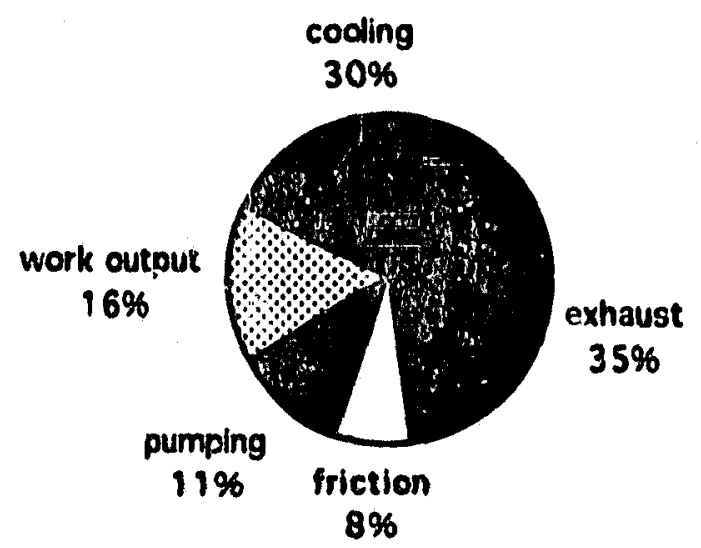

Figure 1.2 Distribution of engine energy (input chemical energy $=100 \%$ ).

A major design parameter of an engine is the compression ratio, $C_{R}$. The theoretical thermal efficlency of an air otto cycle is

$$
\eta=1-c_{R}^{l-\gamma}
$$

where $\gamma$ is the ratio of specfic heats.

Equation 1.1 is plotted in Figure 1.3, where apparently high compression ratios are definitely more efficient. Studies of real engines (Durbin 1980) indicate that fuel consumption Improves by as much as $20 \%$ for a change In compression ratio from 7.5 to 9.6. Thus, Increasing the compression ratio is the princlpal tool avallable to the engine designer for Improving the efficiency of engines. For example, diesel engines, which generally operate with compression ratios of 15-22:1, are supertor fuel consumers compared to spark-Ignited gasoline fueled engines. which typlcally operate at compression ratios of $<10: 1$. 


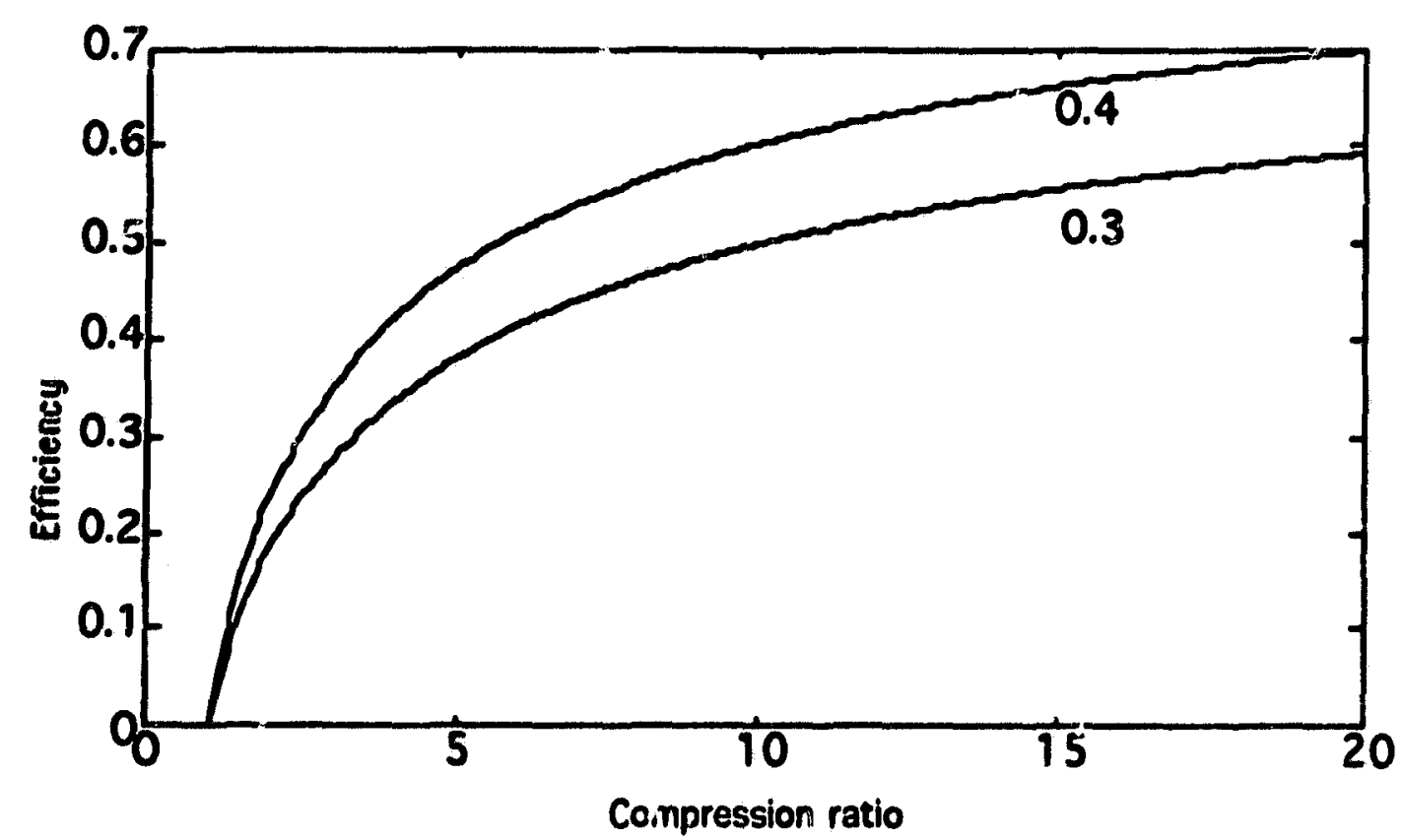

Figure 1.3 Otto cycle efficlency. Numertcal values refer to the value $: \cdot \gamma$, where $\gamma$ is the ratto if specific heats.

\subsection{The Fuel-Engine Relationship}

The compression ratio of an engine is limited by the ability of the fuel used to resist detonation or "knock." Knock refers to the situation where the fuel-alr mixture experlences a sudden energy release. This is caused by the bulk fuel-alr mixture being heated when the plston compresses the fuel-alr mixture, and by the initial release of energy shortly after Ignition, to a point where the end-gas mixture detonates. In Figure 1.4. the combustion chamber pressure shows normal combustion and knock. The oscillatory nature of the pressure signal results from the shock wave 
produced by the detonation reflecting from the chamber surfaces. This is the source of the audible "ping" assoclated with knock.

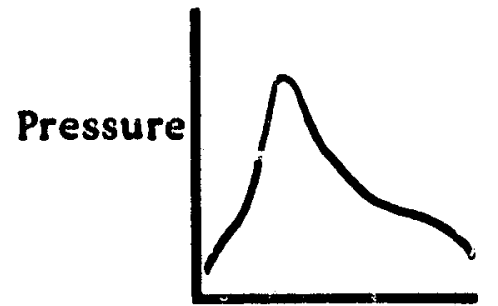

Normal

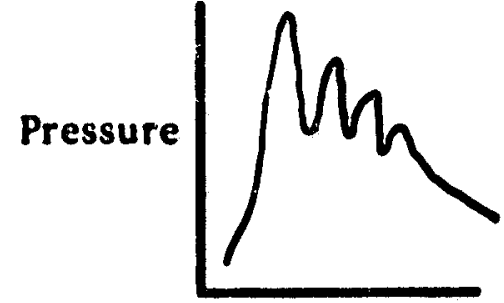

Knock

Figure 1.4 Cylinder pressure with normal combustion and kisock.

Knock is a detrimentai conditton because the sudden energy release causes a high over-pressure inside the combustion chamber, which places a severe inechanical load on the chamber, piston, and assoclated bearings. For a given fuel, the onset of knock occurs above a certain compression ratio. The Research Octane Number (RON) is a measure of the knock resistance of a fuel. For higher RON, the fuel is more knock resistant and the compression ratio ilmit can increase.

Reduction of the knock susceptibility of a fuel at the high end-gas temperatures is accomplished at the refinery in further cracking stages. However, this additional treatment has costs in efficlency of fuel production. because morc cracking stages result in fewer lltres of gasoline from the original barrel of crude oul. 
Knock ing can also be impeded by the use of additives in the fuel. For many yea:s, leat has been used to prevent knock. Lead, however, is environmentally -and now legislatively-unacceptable. Other additives, such as water and more alr, are also well-known ways to reduce the knock susceptibllity of fucl-air mixtures.

The relationship between the fuel characteristics-ignition delay. combustion time, and knock susceptibility-and the engine design parameters is crucial to tive effielency of an engine. The limitation on compression ratio die to knock is a major factor influencing the overall fuel efficiency of the world's entire automotive fleet.

The fuel-engine relationship demands that changes in the characteristics of fuel type be reflected in the engine design parameters and vice versa. This relationship has major implications, though it is often overlooked when vlewed from an Industry-wide perspective. The engine designers and manufacturers ar: looked upon as an Industry separate from that of the fuel makers (oll companles). Instead, all the players should be seen as complementary components of a single transportation industry. Just how Important the fuel-engine relationship is to our transportation system is lllustrated in the next section.

\subsection{The Need for a Hollstic Systems Approach}

In the previous sections, we have seen that increasing the compression ratlo is the prime method for Improving engine efficiency and that high 
compiession engines require spectal high-octane fuels or spectal methods to prevent the occurrence of knock. Up to 1970, the average compression ratio for the gasol'ne-fueled fleet worldwide was approximately $9.5: 1$. A bout that time. legislation was Introduced in California almed at reducing alr pollution caused by automoblle emisstons. The legislation established stringent emission standards that would require engines to reduce significantly the emissions of unburnt hydrocarbons and oxides of nitrogen (NOx).

The ongine manufacturers realized that their engines could not meet these new standards, but the engine designers knew how it could be cione: redesign engines to operate under very lean conditions. This task. however, would require a major effort and a very large capltal investment to cover. among other things, development costs and the cost of retooling plants. The deadline to achleve these new emlssion standards was Imminent and. In practical terms, the engine manufacturers could not redesign and manufacture proven engines to meet this deadilne.

An alternative approach, and one that did not require much time or money, was the use of the catalytic converter. These, by now familiar. objects appeared to keep the pre-1970 engine design Intact by cleaning up the exhaust products. This "quick fix" approach Initlally seemed attractive to the engine manufacturers, except there was as serlous problem. It didn't wo:k. The reason was that a constituent of the fuel rendered the converter inoperative as soon as it was used. The gullty constituent was !.jad, which polsoned the active element of the converter. 
platinum. The engIne manufacturers literally told the fuel makers to "get the lead out" and unleaded fuels emerged into the market place along with catalytic converters. Lead, as noted in the previous section. was primarily an anti-knock agent and its removal forced the fuel makers to produce inore stable (less knock-susceptlble) fuels by means of further refining (cracking) processes. However, these additional refining steps not only make the final product more expensive, they also result in further waste so that ultimately there are fewer litres of unleaded gasoline produced from the original barrel of crude oll.

The unieaded fuels prodiced in the early 1970 's caused the engine manufacturers to reduce the average industry compression ratio dramatically to 7.5:1 to reduce the tendency of the new fuels to knock. In other words, to meet the California emission standards, the catalytic converter solution required more costly unleaded fuels as well as a reduction in the engine compression ratio. The compression ratio reduction from an industry average of $9.5: 1$ to $7.5: 1$ represents a theoretical thermal efficlency reduction of $20 \%$.

The combination of less efficlent engines and the need for more highly refined fuels required an estimated increase of $15 \%$ in crude oll consumption. Unfortunately, the original alm of the California legislation, although well intended, resulted in increased oll consumptioii. Knowing what we do today about hydrocarbon fuel combustion and $\mathrm{CO}_{2}$ emission, we might conclude that the introduction of catalytic converters and their associated unleaded fuels was a blunder. 
Clearly it was not the fault of the original California legislation, but rather of management's deciston to employ the catalytic converter as the means to achleve the new mission standards.

The dectsion to use the converters appears to have ignored the fuel-engine relationship, and demonstrates how major changes taken Ind:pendently by engine manufacturers, forced by legislation, can have serlous consequences for energy use. Instead, the fuel producers and engine manufacturers must be vlewed as interdependent parts of a transportation system. It is refreshing to note that movement towards this new approach ts taking place. In the August 31,1991 , Issue of the Economist, a spectal report on Energy and the Envtronment observed that "Amertca's maln car manufacturers and oll compariles have teen taiking for the past year about the way cll and engiries react. Such co-operation Is a novelty." This "holistic systems" approach is rooted in the fuelengine relationship discussed in the prevlous section.

History is perhaps ready to repeat Itself, though. Again California legislation is requiring $2.10 \%$ of the new fleet sold in that state in the year 1999 to be made up of zero emission (1.e., electric) vehicles. A laudabie goal, but will nuciear power plants mushroom to meet the Increased electrical demand? 


\section{$1.5 \quad$ Outine of this Thesis}

The thrust of this thesis, as mentioned in Section 1.2. is to study the Ignition prncess, because of the environmentally motlvated movement towar is the use of leaner burning engines and alternative fuels such as compressed natural gas. These changes have led, and will inevitably continue to lead to Ignition problems.

In the thesis I will address the ignition problem in a two-fold way. First, In Chapter 2. I will look at how some of the characteristics of lear. combustion manifest themselves. Some practical ignition techniques wt'] be presented to show that some of the lesn-burn combustion problems can be overcome. Then, to shed light on the effects of the Ignition techniques described in Chapter 2. I will shift the focus of the thesis to the more specific problem of the early phase of spark Ignition. To this end, Chapter 3 reviews a thermal model of ignition from a 3 imple ignittion source. This model has features found in many Ignition theorles described in the literature, some of the more important ones of which are brlefly reviewed. Most thermal theortes of Ignition treat the energy provided by the electrical discharge as a point source. delivered infiritely fast and creating a spherically symmetric ignition kernel. Chapter 4 challenges this position by reviewing the work of many investigators who have ciearly shown that the temporal characterlstics of the discharge have a profound effect upon Ignition. Photographic evidence of the early phase of ignition, as well as other evidence from :ise literature, is also presented. clearly demonstrating that the morpholugy of spark kernels in 
the early phase of development differs from that held in the dominant view of the past 50 years.

Chapter 5 presents a new perspective for ignition, a fluld dynamic point of vew. I vill show how the common Ignition devices of Chapter 2 can be classiffed according to fluld dynamics. I will then present a model, which extends a prevtously established mixing model for plasma jets, to the realm of conventional adal discharges, and compare the model behaviour to some of the limited data avallable.

In Chapter 6. the effect of heat addition from combustion on the evclution of spark kernels will be included in the model of Chapter 5, and Ignition criterla discussed. Chapter 7 presents the concluslons of this thesis. 


\subsection{Combustion in a Box}

We begin our study of spark Ignition by examining a very simple closed combustton system. lllustrated in Figure 2.1. The system consists of an enclosed vessel that can be pressurized up to four atmospheres with any desired mixture ratio of fuel and alr. Ignition devices to be studied are attached to the vessel and varlous parameters-such as stored electrical energy, discharge current, and voltage-are measured. The ignition device is "fired" and a plezoelectric pressure traisducer records the interlor pressure of the vessel during the combustion event.

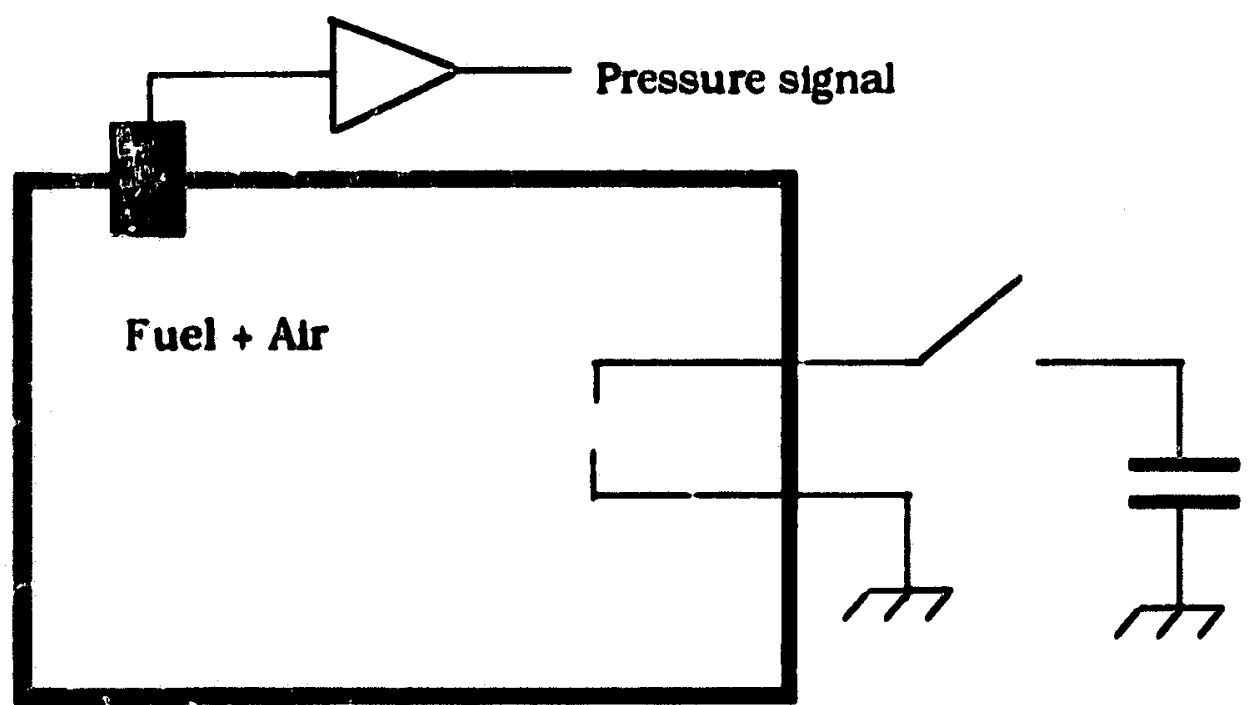

Figure 2.1 Simple closed combustion system. 
A sample pressure trace irom a combustion event, shown in Figure 2.2. uses a conventional spark Ignition source, standard automotive industry electronics, and propine, as the fuel. Propane has a lame speed similar to that of gasoline and is chosen for that purpose. The figure also helps to define two combustion parameters of Interest: Ignition delay time and combustion duration.

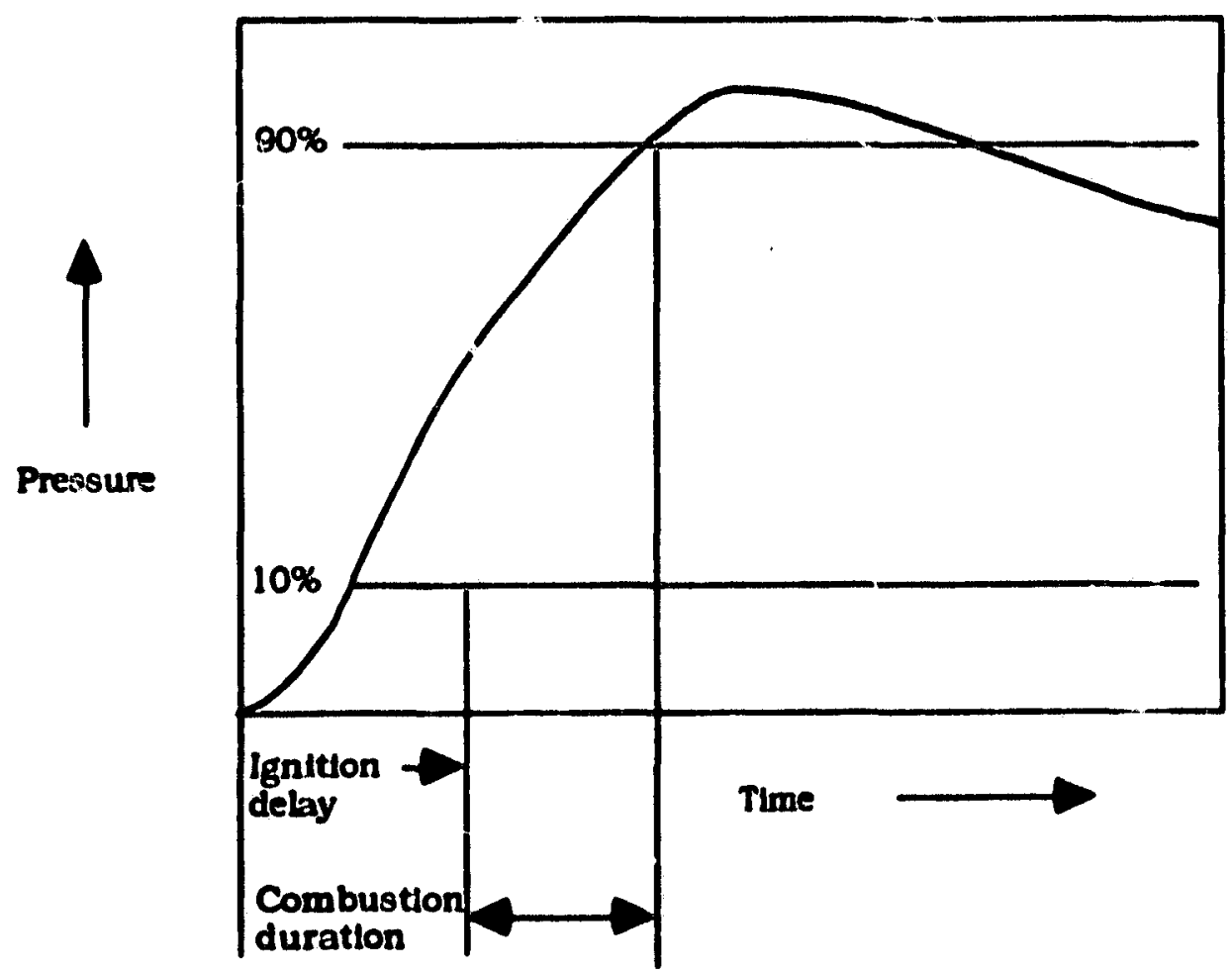

Figure 2.2 Priessure trace fiom simple combustion system. The percentages refer to the peak pressure.

An experiment is now performed where the only parameter varled is the normalized alr:fuel ratio. The normalized alr:fiel ratio, $\lambda$, is obtalned by taking the ratio of the alr and fuel volumes (or the masses) present in the mixture and dividing by the chemically correct alr:fuel ratio. For example. 
the chemically correct or stolchlometric ratio for an alr-methane mixture is 9.55: 1. Stolchlometric mbrtures would thus have a normalized alr:fuel ratio of $\lambda-1.0$. Lean mixtures would have $\lambda>1.0$ and rich mixtures wculd have $\lambda<1.0$. In the experiment, the normalized alr:fuel ratio is changed from stolchiometric $(a-1.0)$ to increasingly leaner condictons by Increments of 0.1. Results of such an experiment are shown in Figure 2.3. Most notable in the results is the increase in both the ignition delay time and combusistion duration as the alr:fuel ratio becomes learier.

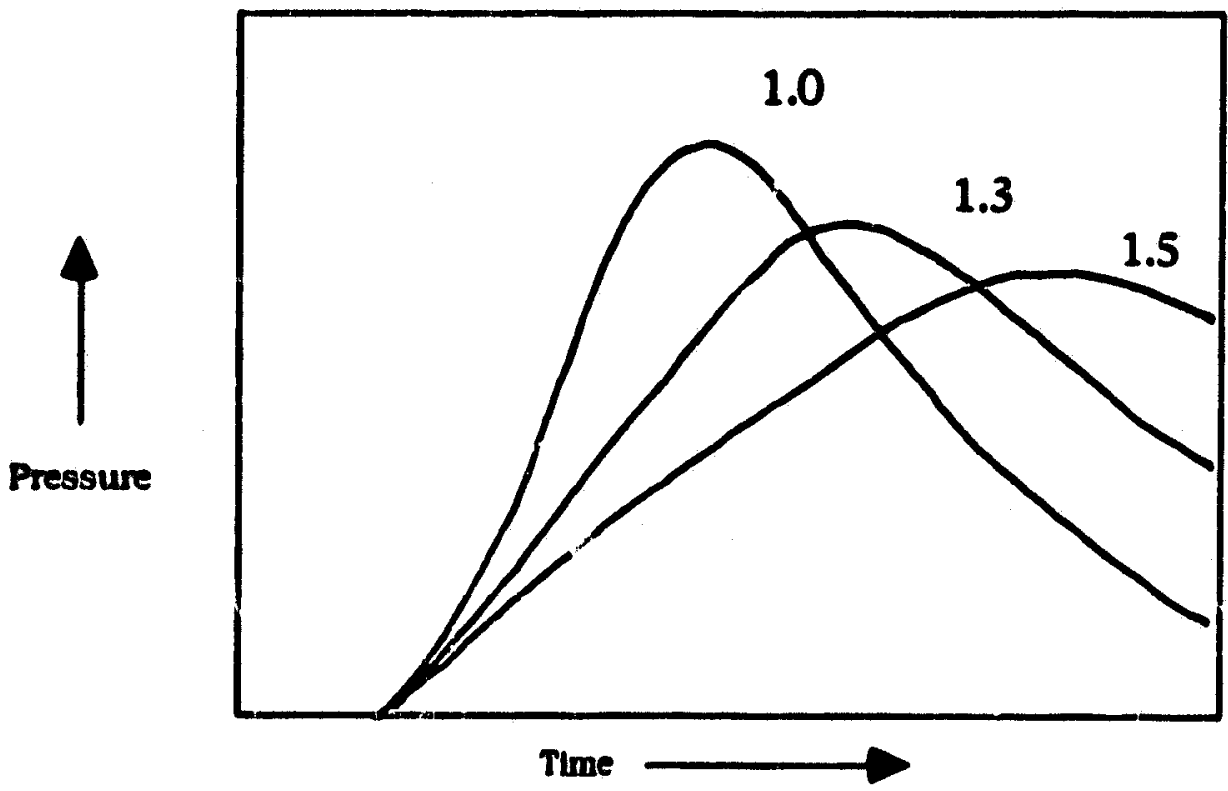

Figure 2.3 Pressure-time historles as the mixture becomes increasingly leaner. Numbers refer to normalleed alr:fuel ratio $\lambda$.

A second experiment is riow performed with this simple combustion system. first by using a stolchiometric mixture of propane and alr, and second by substituting the propane-air mixture with a stolchlometric methane-air mixture. The purpose of this experiment is to lllustrate the effect on the combustion system of changing fuels. Methane's flame speed ts significantly slower than propane's. The results (Figure 2.4) show that 
switching between propane (and, by inference, gasoline) and methane has an effect similar to that of golng to leaner propane-air ( $c$ : gasoline-alr) mixtures.

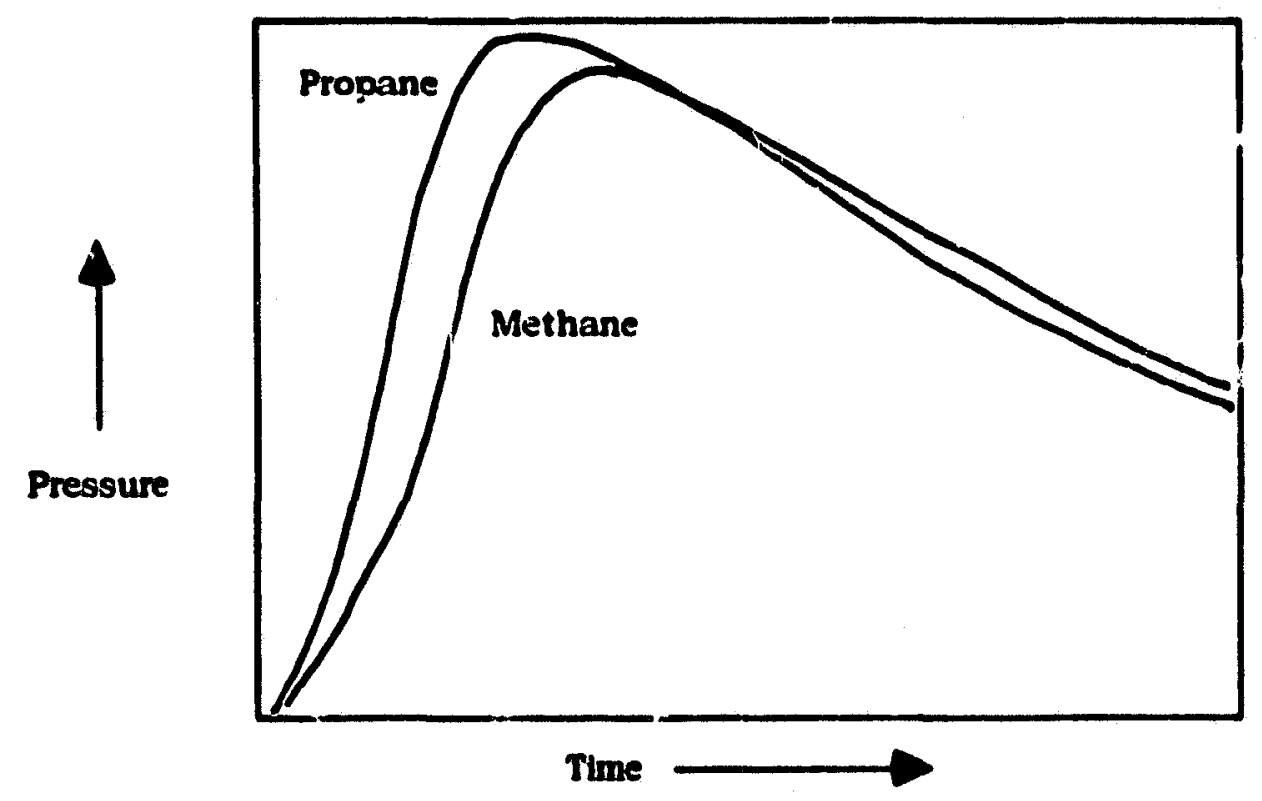

Figure 2.4 Effect of changing fuel from propane to methane.

From these simple experiments. It is evident that lean-burn cuiditions or alternative fuels like methane present dramatically altered operating cond!'jons. For combustion systems such as IC engines that requil. a rapid combustion processes, output power may be severely degraded under these new operating conditions.

\subsection{Ignition Techniques for Lean-Burn Conditions}

A conventional ignition system for IC engine applications consists of a small (1 - $2 \mathrm{~mm}$ ) gap separating two electrodes which. when triggered. discharge a few millijouies of stored electrical energy over a period of a few 
milliseconds. This type of discharge, as shown in the previous sectio.l. results in slow combustion speeds when mixtures are lean. In this section. we look at some techniques that reduce ignition delay and combustion duration in lean mixtures. First, we examine results of experiments empioying these ignition techniques in qulescent combustion bombs. We then follow the transition of the observed effects in bombs as these techniques are used in more reallstic IC engine combustion chamber environments.

\subsubsection{Plasma Jet Ignition}

Ignition by plasma jet has received much attention during the past decade. since the results of the first experiments using this technique were reported by Topham et -1. (1975) and Wienber et al.(1978). The basic design of a plasma fet system consists of coaxial electrodes, one of which is recessed into a blind cavity. Stored electrical energy is discharged through this gap In 20 - $50 \mu$ sec. Reviews of the published work on plasma jet ignition can be found in Dale and Oppenhelm (1981) and Clements (1984).

Orrin et al. (1981) have argued that plasma jet ignition derives its impressive efiects from the production of hydrogen radicals that augment the combustion proce $: 9$. Their work was extended by the following sertes of experiments. A plasma jet igniter was mudified to accept different gases bled into the cavity. The details of the experiment are contained in Ridley et al. (1984) (see Appendix I) The results are discussed here. 
Lean methane-air mixtures in a qulescent bomb were ignited by the modifled bleed plasma jet. Pulsed shadowgraph photographs were used to estimate the flame kernel's mean area as a function of timc. These results are shown in Figure 3 of Ridley et al. (1984) (see Appendix I) where the radius of the growing kernel is plorted vs time for three types of Ignition devices: a conventional Igniter, a plasma jet. and the modified bleed plasma jet. It can be seen that adding different gases to the cavity of the plasma jet has a measurable effect on the growth rate of the kernel.

Measurements of the rate of pressure rise (dP/dt) in the bomb after Ignition with the bleed plasma jet are shown in Figure 4 of Ridley et al. 1:984) (see Appondix I), where the maximum dP/dt observed for a given bleed gas is plotted vs the heat of combustion of the bleed gas. The measurements are for a very lean ambient mixture $(\lambda-2.0)$. The rate of pressure itse appears to be strongly correlated to the heat of combustion for the bleed gas and not to the number of $\mathrm{H}$ atoms per mole of the associated bleed gas.

The plasma jet ignition technique seems to be promising for lean-burn conditions. However, the large energy requirement ( $1 \mathrm{~J}$ per firing) and, more particularly, the serious erosion of the electrodes due to the high current levels in the discharge suggest that practical implementation of this technique may be difficult.

\subsubsection{Pufi Jet Ignition}

Once the plasma jet's plume was understood theoretically (Topham et al. 1983), a mechanical analogue of the plasma jet was developed (Pitt et al. 
1984). This technique, known as "puff jet ignition." attempts to produce the positive ignition qualities of the plasma jet, but without the high power requirement or the concomitant electrode erosion.

A puff jet ignition experiment, in a combustion bomb configuration, is shown in Figure 2.5. In the puff jet technique, a very smail amount of gaseous fuel (e.g., methane! is puffed Into the combustion chamber through a fast-acting vaive. The puff rapidly mixes with the lean, ambient mixture as the puff advances into the chamber. Conventional electrodes are placed downstream from, the valve orifice (distance $0.5-1.0 \mathrm{~cm}$ ) and the coinventional dischirge clrcult is triggered to fire at a time: $\Delta t$ after the valve opens. A more detalled description of this technique is avallable in Appendix 1.

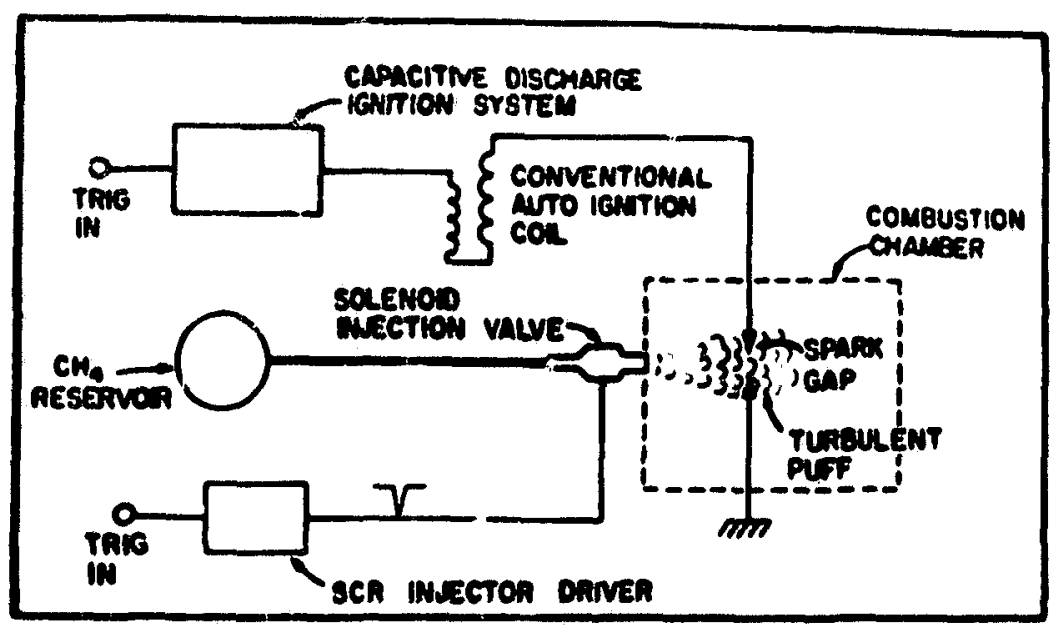

Figure 2.5 Schematic of puff jet system.

Figure 3 of Pitt et al. (1984) (see Appendix I) shows a schlieren Image of the turbulent element produced by the puff jet compared with that produced by 
a plasma jet in atr. The similarity of the two turbulent elements is striking. Results of an experiment when lean $(\lambda-1.3)$ mixtures of methane-air are Ignited by three Ignition sources are shown in Figure 2.6. In this figure, the pressure-time historles of the plasma jet and puff jet are very similar. Therefore, both tginition delay and zombustion time of lean mixtures can be reduced using an ignition device that resembles a plasma jet but does not require $1 \mathrm{~J}$ of stored energy, or suffer a limited life due to electrode erosion.

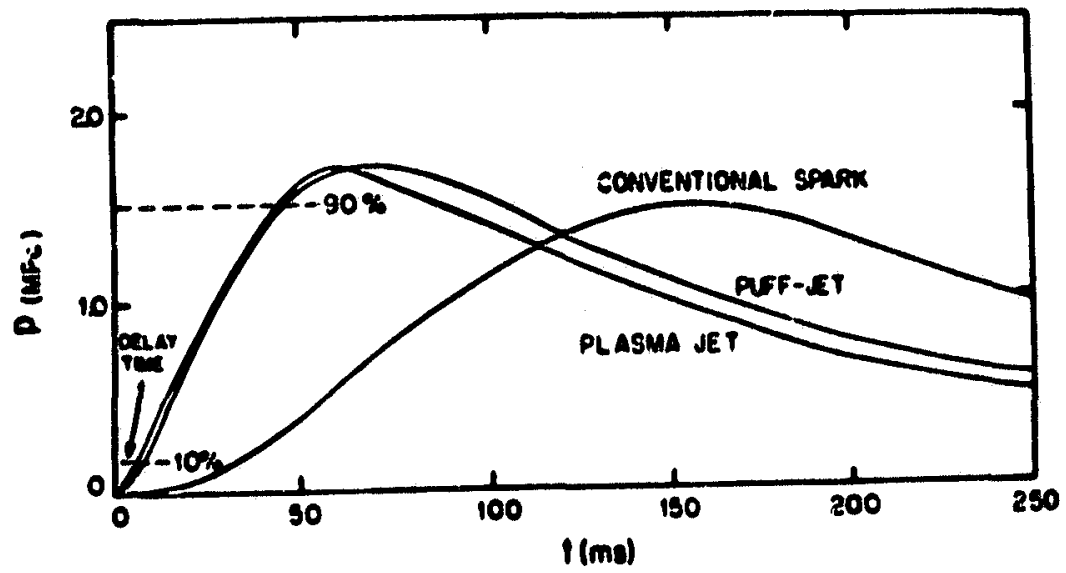

Figure 2.6 The relattonship of bomb pressure $p$ and time $t$ for the puff fet. plasma jet and conventional spark at a starting bomb pressure of $5000 \mathrm{kPa}$ and a normalized alr:fuel ratto of 1.3. 
2.2.3 Fast-Discharge Ignition

A serles of experiments into the physics of the spark discharge and its Ignition propertles was carried out by Investigators at the University of Stuttgart. Significant progress was made towards understanding the energy exchange between a discharge and the local mixture.

Maley et al. (1978) showed striking results of Ignition produced by conventional electrode configurations employing fast-discharge (<100 ns) circuits with stored electrical energies of approximately $30 \mathrm{~mJ}$. The authors observed rapid growth rates of ignition kernels in lean mixtures.

The reduced ignition delay and combustion times in lean mixtures are similar to those times produced by the previous ignition devices.

\subsubsection{Conclusions from Combustion Bomb Experiments}

The results reviewed above demonstrate that Ignition delay and combustion times of very lean mixtures can be significantly reduced with practical techniques using apparently different approaches. These results, however. are for qulescent, homogeneous mixtures. What happens in conditions of higher pressures and varying degrees of amblent turbulence is most relevant to ignition device application.

In the next section, actual engine experiments using the Ignition devices discussed here are revlewed. We Investigate how the results obtalned from 
combustion bomb experinents translate to combustion chamber conditions more typlcal of engines.

\section{$2.3 \quad$ Ignition Experiments in Engines}

The primary difference between engine combustion chambers and the simple quiescent combustion bomb is the level of amblent mixture motion. Residual turbulence from the intake of a fresh alr-fuel mixture into the combustion chamber is subsequently dominated by turbulence produced by the rapid upward motion of the piston. Modern combustion chamber design focuses on enhancing the intrke (swirl) turbulence and the turbulence produced by the piston motion. The inotivation for enhancing the level of amblent turbulence is to speed up the combustion process, especially for lean alr-fuel mixtures.

Instead of a comprehensive review of work Investigating the effects of a multitude of engine parameters on the combustion process, we will now revlew some selected work to lllustrate the transition from combustion bomb experiments to experiments Involving real engines. Observations and conclusions drawn from qujescent bomb experiments must be mitigated by the important influences of turbulent flows of various scales inside real engine combustion chambers. 
2.3.1 Plasma Jet Ignition in an Internal Combustion Engine

In Section 2.2.1, we discussed the dramatic effects observed when a quiescent mixture, especially a lean mixture, is ignited by a plasma jet. In a serles of experiments motjvated by the interest in .nethani: as an alternative fuel, the effect of a plasma jet Igniter on a simple, single cylinder engine was examined (Pitt and Clements 1983). The engine was run at a constant speed. with a wide open throttle. The air:fuel ratio was varled by altering the alr flow but keeping the methane flow constant at all times. Further detalls can be found in the Appendix I. A comparison between brake horse power (BHP) produced using a plasma jet and a standard auto industry capacitive discharge Ignition system(CDI) is shown in Figure 1 of Pitt and Clements (1983) (ste Appendix I).

The most interesting result obtained was from an analysis of the combustion chamber pressure time historles. An example. shown in Figure 2.7. Illustrates the change in the product $p V^{\prime}$ where $p$ is the cylinder pressure, $V$ is the cylinder volume, and $y$ is the ratio the mixture's specific heats. Thls product is constant for isentroplc processes (compression or expansion), but changes dramatically during the combustion process. The $\log p V^{\gamma}$ curves for the plasma jet and the capacitive discharge ignition system are almost Identical, except that the latter was itred more than 2 ms before the plasma jet in the example shown. It therefore appears that the primary effect of the plasma fet is to reduce the ignition delay. However, 
dramatic reduction of the combustion time is not observed, unlike in combustion bomb expertments.

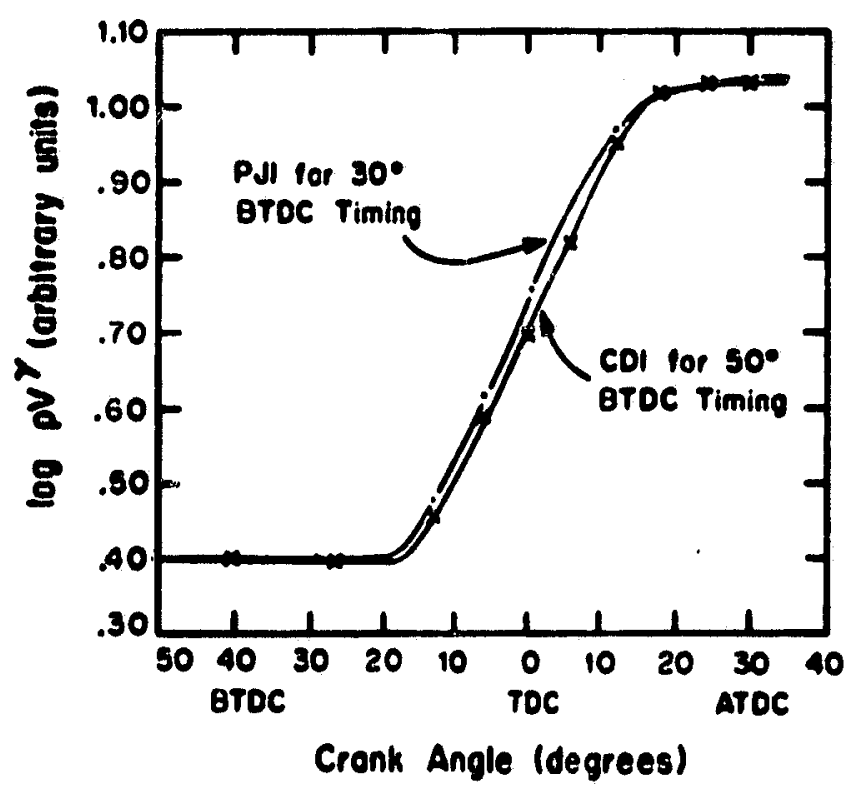

Fgure $2.7 \log p V^{\prime}$ vs crank angle for $\lambda=1.0$ and optimal time range for both ignition sources. Engline speed is $2000 \mathrm{rpm}$.

\subsubsection{Pufi Jet Ignition in Internal Combustion Engines}

The application of the puff jet ignittion to IC engines was first reported by Pitt et al. (1984). An example of combustion chamber pressure from a test engine using puff Jet, plasma jet, and conventional Ignition systems is shown in Figure 2.8. These results Indicate that puff jet ignition characteristics are comparable with those created by plasma jet Ignition. as seen in the prevlous combustion bomb experiments. Continuous running engine tests (Fisher et al. 1986) further demonstrate the simllarity of puff jet and plasma jet ignition. 

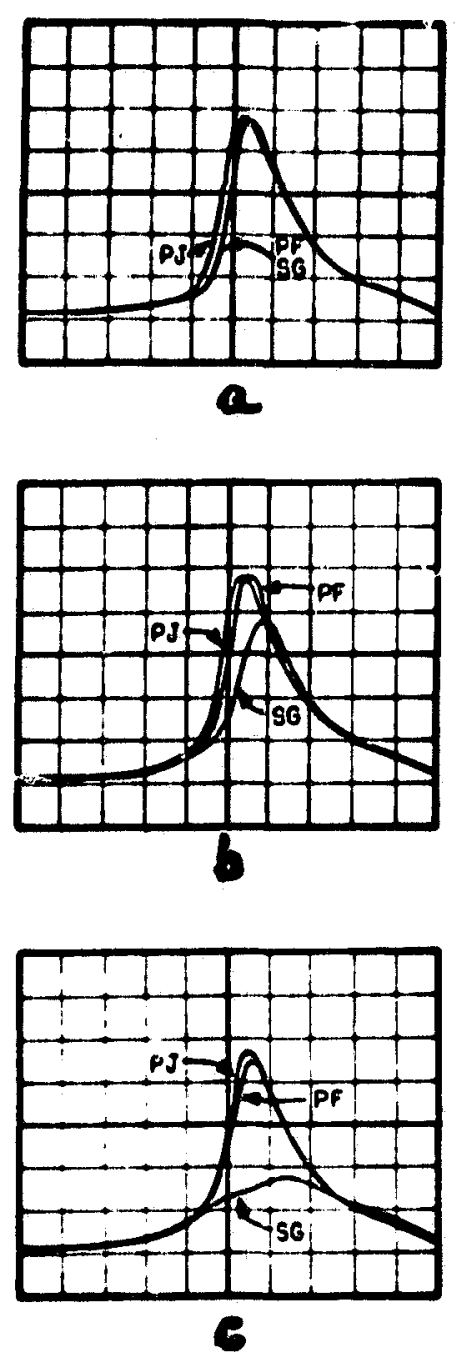

Figure 2.8 Vartation of average pressure waveforms as a functton of normalized alr:fuel raito. Ignitton timing fixed at $50^{\circ}$ BTDC. Vertical scale; $440 \mathrm{kPa} /$ div: hortzontal scale; $36^{\circ}$ CA/div. TDC is located at the centre line of the grid. Ignition sources denoted by: PJ. plasma jet: PF, puff jet: SO, extendisd electrode spark gap. (a) $\lambda=1.0 ;$ (b) $\lambda=1.3$; (c) $\lambda=1.6$. Note in $(a)$, the puff jet and spark gap sources produced averaged pressure waveforms that are identlcal. 


\subsubsection{Fast-Discharge Ignition}

Maly et al. (1983) reported experiments on test engines using fast-discharge techniques. Reduction of ignition delay for lean mixtures and extension of the lean misfire limit were observed. These effects are identical to those observed under similar conditions using the plasma jet and puff jet techniques.

\subsection{Conclusion}

Practical means to Ignite lean mixtures do exist. The techniques discussed all produce similar results. Nevertheless, we must conclude from the preceding results that moving from the qulescent combustion bomb to the more turbulent combustion chamber envtronment of an engine reduces the impact of these ignition techniques. The predominant effect of the techniques over conventional ignition systems is the reduction of ignition delay. Combustion duration is not affected. The bulk turbulence of the engine combustion chamber determines the overall flame propagation speed. and hesice the combustion duration. The ignition device can, however. affect the early (1-2 ms) evolution of the combustion event in a real engine. It is for this reason that we shift the focus of this thesis to that early phase of ignition. 


\section{3 The Thermal Approach to Spark Ignition}

The focus of the the sis will now move from a discussion of ignition device examples and the practical problems assoclated with lean burn or alternative fueled IC engines to the more specific problem of the early phase of spark ignition. There are two reasons for doing so: the need to examine the divergent electrical discharge ignition theories in the Iterature; and the need to understand, from basic princtples, the Ignition devices discussed in Chapter 2.

We begin by examining the simplest electrical discharge Ignition devicethe axtal electrode gap. The basic ignition problem can then be stated: How does the spark energy deposited in the gap become distributed from the narrow breakdown channel into the spark kernel structure observed, and what processes govern the evolution of the structure in a comr ustible mixture? To begin to answer these questions, we revlew a physical model that is basic to most models of spark ignition.

\subsection{Basic Thermal Model}

A recent edition of a well-known moriograph on combustion (Glassman 1987) Includes a theoretical description of spark Ignition based on the thermal approach of Zeldovich et al. (1940). The thermal model assumes that the energy of a capacitive spark discharge is delivered to the combustible mixture as a point heat source, and that thermal diffusion 
will lead to an exponential temperature distribution throughout a spherically symmetric spark kernel. The model, though simple, represents current commion understanding of the spark ignition process and it is therefore Important to revlew. We will show in Chapters 4 and 5. however, that this viewpoint misrepresents the basic physical process Involved.

For ignition to happen, the spark kernel should achleve or exceed a certain radius in a time faster thain the cooling (due to conduction) can reduce its temperature below the laminar flame temperature. It is instructive to review the basic assumptions and equations of this theory.

First, it is assumed that the energy $E=1 / 2 C\left(V_{1}^{2}-V_{2}^{2}\right)$, where $V_{1}$ is the Initial voltage and $V_{2}$ is the voltage after the discharge, is deposited in the spark gap as a point source. This energy then spreads according to the spherically symmetric heat equation:

$$
\left(\frac{\partial}{\partial t}-\Omega \frac{\partial^{2}}{\partial r^{2}}\right) T=0
$$

where $\Omega=k / c_{p}$ and the boundary conditions are $T=T_{0}$ at $r=\infty$ and $\partial \mathrm{T} / \partial \mathrm{r}=0$ at $\mathrm{r}=0, \infty$.

The solution of (3.1) with these boundary conditions is:

$$
T-T_{0}=\frac{Q}{c_{p} \rho(4 \pi \Omega t)^{\frac{2}{3}}} \exp \left[\frac{-r^{2}}{4 \Omega I}\right]
$$


The criterion for ignition is that the time requised for the on-axds temperature (T(r=0)! to drop by an amount $\phi$ must be greater than the reaction time in the combustion zone of a laminar flame. The temperature difference $\phi$ is taken to be the difference between the laminar flame temperature $T_{f}$ and an estimated Ignition temperature $T_{1}$.

The cooling time $t_{c}$ can be estimated from

$$
t_{c} \approx \frac{\phi}{\left(\frac{d T_{,-0}}{d t}\right)_{T=T}}
$$

Before evaluating (3.3), the energy 9 in (3.2) must be defined. This energy is taken to be the energy required to heat a spherical volume of radius $r_{f}$ from $T_{0}$ to $T_{f}$. Thus:

$$
Q=\frac{4}{3} \pi r^{3} c_{p} \rho\left(T_{1}-T_{0}\right)
$$

Evaluation of (3.3) using (3.4) ylelds:

$$
t_{c}=0.14\left[\frac{\phi}{\left.T_{1}-T_{0}\right]}\right]\left(r_{1}^{2}, / \Omega\right)
$$

An estimate for the reaction time $t_{r}$ can be obtalned from knowledge of the laminar flame speed $S_{L}$ and thickness $\Delta$. The reaction time is related to those quantities through: 


$$
\Delta=\mathbf{S}_{\mathbf{L}} \mathbf{t}_{\mathbf{r}}
$$

The laminar flame speed. $S_{\mathcal{L}}$ can be determined through the calculation first presented by Mallard and Le Chatlelier (1881). It is based on the assumption that the heat conducted from zone I (see Figure 3.1) would equal that amount necessary to ralse the temperature of the unburnt gases to the ignition temperature $T_{1}$.

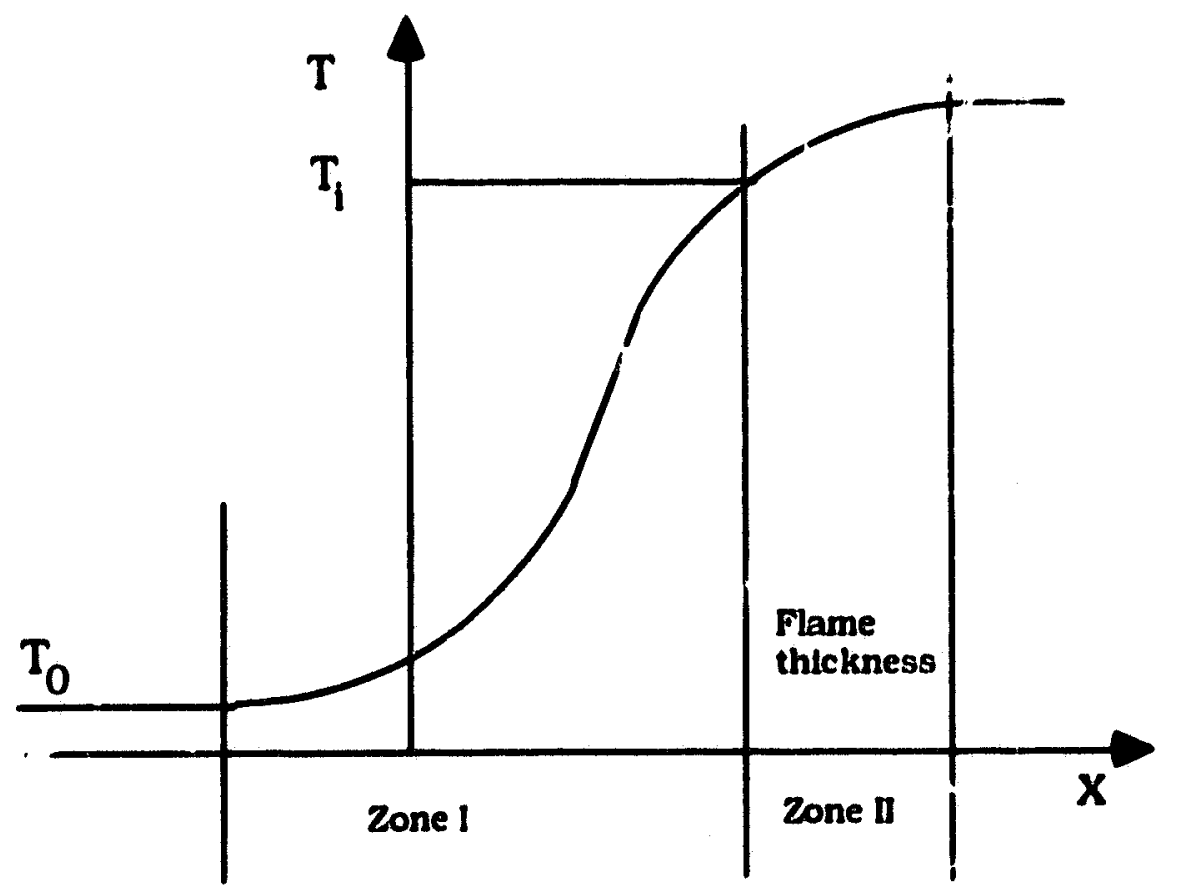

Figure 3.1 Mallard-LeChateller description of a laminar flame temperature profle.

The enthalpy balance across the flame Is:

$$
\frac{d m}{d l} c_{p}\left(T_{1}-T_{0}\right)-k \frac{d T}{d x} A
$$


where $A$ is the cross-sectional area perpendicular to the flame front. The mass rate $\mathrm{dm} / \mathrm{dt}$ is the rate at which the combustion wave consumes the unburnt gas. The combustion wave is propagating at the laminar flame speed $S_{L}$ and this is related to the mass rate by:

$$
\frac{d m}{d t}-\rho S_{L} A
$$

The temperature derivative can be approximated by assuming the temperature profile to be linear:

$$
\frac{d T}{d x} \sim\left(T_{f}-T_{0}\right) / \Delta
$$

Substituting (3.8) and (3.9) Into (3.7) yields:

$$
S_{L}=\frac{\Omega}{\Delta}\left(T_{f}-T_{i}\right) /\left(T_{f}-T_{0}\right)
$$

Using (3.10) in (3.6), we obtain an expression for the reaction time $t_{r}$ in terms of the temperatures difference $\phi$ :

$$
t_{f} \approx \frac{\Omega}{S_{L}^{2}} \phi /\left(T_{1}-T_{0}\right)
$$

where $\phi /\left(T,-T_{0}\right) \ll 1$ has been used.

This reaction time is a factor of two faster than that calculated by Zeldovich et al. (1940), but it lllustrates the basic assumptions involved. 
Now, with an expression for $t_{c}$ and $t_{r}$-equatiors (3.5) and (3.11)-the ignition criterion, $t_{c} \geq t_{r}$, can be calculated explicitly as:

$$
r_{,}^{2} \geq \Omega^{2} /\left(0.14 S_{L}^{2}\right)
$$

The ratio $\Omega / S_{L}$ has the dimension of length and can be interpreted as being related to the flame thickness because equation (3.10) can be put into the form:

$$
\frac{\Omega}{S_{L}}=\left(T_{l}-T_{0}\right) \Delta / \phi
$$

Therefore:

$$
r_{1} \geq 2.67\left(T_{j}-z_{0}\right) \Delta / \phi
$$

The physical implication of (3.14) is that the equivalent heat radius $r_{f}$ must be significantly greater than the laminar flame thickness $\Delta$.

Furthermore, the concept of minimum ignition energy can be introduced. The value $r_{m i n}$, as defined by the right-hand side of the inequality (3.12), Is:

$$
r_{\min }=7.1 \frac{\Omega}{S_{L}}
$$

Therefore

$$
Q_{\min }=\frac{4}{3} \pi r_{\min }^{3} c_{p} \rho\left(T_{1}-T_{0}\right)
$$




$$
-1.5 \times 10^{3}\left(\frac{\Omega}{S_{L}}\right)^{3} c_{p} \rho\left(T_{1}-T_{0}\right)
$$

The main result of the thermal approach to ignition is the estimate of $\theta_{\min }$ glven by (3.16) and its apparent dependence on physical parameters. (such as the thermal diffusivity), and chemical parameters, (such as flame speed). Much effort has gone into measuring $Q_{\mathrm{mln}}$ for various fueloxidizer mixtures, but it was recognized early on that the experimental values of $\mathrm{g}_{\mathrm{min}}$ were strongly affected by spark gap length. There exdsted a spark gap length $d_{q}$, below which ignition of the mixture was not possible, and this length was termed the "quenching distance". The Interpretation was that excessive cooling by the electrodes caused quenching of the Ignition kernel at spark gap lengths less than $d_{q}$. It is Interesting to associate the quenching distance $d_{q}$ with $r_{\min }$ given by (3.15). which would imply that $g_{\min }$ is proportional to $d_{q}{ }^{3}$.

\subsection{Theory of Lewis and von Elbe}

Another thermal theory, that of Lewis and von Elbe (1961), was widely quoted for many years. It is based on an "excess enthalpy" assumption which presumes that in a thin shell ahead of a spherically symmetric flame front. the enthalpy is greater than in the surrounding burned or unburned gases. Agaln, as in the theory of Zeldovich et al. (1940), a critical diameter for the ignition kernel must be attained such that the excess enthalpy is supplied by the heat content of the burned gases in 
the kernel. allowing the combustion wave to propagate. The ignition source must provide the minimum ignition energy to achieve this critical kernel size. Lewls and von Elbe (1961) calculate It to be:

$$
Q_{\min }=s t d_{Q}^{2} \frac{k}{S_{L}}\left(T_{b}-T_{0}\right)
$$

where $T_{b}$ is the burned gas temperature. This relationshlp was tested by Lewis and von Elbe and by Calcote et al. (1952) who found $Q_{\min }$ to be proportional to $d_{q} 2$. They measured minimum ignition energles for quiescent, room-temperature hydrocarbon mixtures at atmosphertc pressure. Typical U-shaped Ignition curves were obtained, Indicating minimum ignition energles in the range of $0.1-1 \mathrm{~mJ}$, and these occurred at equivalence ratios of $1.2-1.5$. The excess enthalpy assumption necessary for flame propagation in their model has been criticized by Linnett (1952) and others, as experimental efforts to confirm the exdstence of the excess enthalpy "bump" preceding a flame front have falled to detect such an effect.

\subsection{Ignition in Flowing Gases: Theory of Swett}

Swett (1957) examined the situation of Ignition In flowing gases and calculated $Q_{\min }$ based on the assumption that, unlike in the previous models, the ignition kernel would suffer heat loss primarlly through eddy diffusion. Swett derived a complex expression for $\boldsymbol{Q}_{\min }$ which was substantiated by limited experimental data. His results indicated an lincrease in $\theta_{\min }$ with increase in mixture flow velocity or turbulence 
Intensity, but showed that the scale of the turbulence had little effect on $Q_{\mathrm{min}}$. DeSote $(1971)$ confirmed these results.

\subsection{Theory of Ballal and Lefebvre}

Probably the most extensive Investigation Into spark Ignition In recent years has been performed by Ballal and Lefebvre. Although their interest was investigating conditions more typ/cal of gas turbine systems (1.e., turbulent flow at sub-atmospheric pressure), their approach and results have had much influence.

Their theory, based on observation of flame propagation in flowing mixtures, revealed that the heat release mechanism in the flame zone was very dependent on the level of turbulence (Ballal and Lefebvre 1975). The interpretation of this observation was that, under conditions of low turbulence, burning rates are enhanced by the effects of increased flame surface area caused by the wrinkling of the flame due to turbulence. Ballal and Lefebvre (1975) claim that under conditions of high turbulence, the Intersection of the turbulent eddies, which have fine scale structure, creates a very large total flame surface. These model calculations are relatively simple and yet the physical basis has had a lasting Impact on many other Investigators.

The minimum ignition energy is obtained by assuming, as the criterion for Ignition, that the principal dimensions of the kernel should everywhere equal or exceed the quenching distance. A sphere of 
diameter $d_{q}$ heated to the adlabatic flame temperature is the minimum volume for a spark kernel. and this can be used to compute an estimate of $\mathbf{9}_{\mathrm{min}}$ :

$$
Q_{\min }=\pi / 6 c_{p} \Lambda T d_{q}^{3}
$$

Using the expressions derived for $d_{q}$ for the two cases discussed, we obtain:

$$
\begin{aligned}
& Q_{\min }=\pi / 6 c_{p} \Delta T / A \Omega\left(S_{L}-0.16 u^{\prime}\right)^{-1} \quad \text { low turbulence } \\
& \left.Q_{\min }=\pi / 6 c_{p} \Delta T / H \Omega\left(S_{T}-0.63 u^{\prime}\right)^{-1}\right)^{3} \text { high turbulence }
\end{aligned}
$$

Experiments testing these relationships were conducted by Ballal and Lefevbre (1977) and excellent agreement was obtalned. However. all their data were at sub-atmosphertc pressures. Unlike Lewls and von Elbe (1961). Ballal and Lefevbre (perhaps gleefully) pointed out that their results predicted $Q_{\min }$ proportional to $d_{q}{ }^{3}$ as in the approach by Zeldovich et al. (1940). Clearly then. a basic difference between theorles exdsts, but experiments supporting both have been reported.

\subsection{Thermal Diffusion Model of Ko, Arapaci and Anderson}

Recent work by Ko et al. (199i b) con Inues the Investigation of spark ignition from the point of vlew of a thermal diffusion process. The model 
assumes that a spherically symmetric flame kernel evolves by heat diffusion alone. Solutions to the convection-free energy conservation equations are presented, based on the asymptotic solution method of Champion et al. (1986) and Deshales and Joulin (1983). The solutions are noteworthy because of the extstence of an unstable equillbrium flame radius which is a function of the physlochemical properties oi the mixture. An Ignition criterion is developed that requires successfully propagating flames to exceed this critical radius. Supporting experimental work (Ko et al. 1991 a) showing measurements of flame kernel radil in qulescent mixtures demonstrates the model behaviour well.

\subsection{Discussion}

The thermal model discussed in this chapter has features common to most thermal theortes. For example, the dominant process in the early development of a flame is a balance between the heat released by the exothermic reactions and the heat lost by conduction to the unburnt mixture. The spark energy is used only to ralse a small volume to the flame temperature; the heat balance is left to do the rest. Temporal characteristics of the discharge largely ignored in this approach and, if Included in some approaches, they appear through initial conditions.

The concept of minimum ignition energy is a central theme in most thermal models and it is based largely on the laminar flame speed and the previously mentioned balance between heat release and conduction. 
The laminar flame speed is a number assoctated with a fully developed flame. and its use in the very early phase of spark kernel development may be inapproprlate. Furthermore. data published in the literature are conflicting about such quantities as $Q_{\mathrm{min}}$ and the optimal discharge times that fall to differentiate between thermal models.

In the next chapter, the effect of the spark discharge's temporal characteristic on kernel growth is examined. We also review imaging data of real spark kernels in order to clearly establish their structure. 


\section{Spark Kernel Dynamics and Morphology}

The relevant literature shows us that spark kernels have been the subject of scrutiny since 1945. Our purpose is not to review all this work; Instead, we will direct our attention to two main aspects of spark kernels. First, what are the most important characteristics of electrical discharges that produce the spark kernels? Second, what is the observed structure of spark kernels produced by electrical discharges?

Chapter 3 addressed the above two questions in the following way: the main characteristic of the electrical discharge, from the point of view of Ignition, was its energy. Secondly, the type of spark kernel structure produced was spherical. These two features lle at the basis of must thermal Ignition models and have permeated much of the thinking about Ignition for the past $\mathbf{4 0}$ or $\mathbf{5 0}$ years. In this chapter we challenge this point of vlew.

We begin by revlewing work which clearly shows how the temporal characteristics of the discharge have a profound effect on ignition. Next we present Imaging data of spark kernels, both new and from the Iterature, and demonstrate that the morphology or spark kernels, in the early phase of development, is distinctly non-spherical by nature. 


\subsection{Characteristics of the Spark Discharge}

In the thennal ignition models of the previous chapter. the only attribute of the spark discharge taken Into account is the energy deposited in the gap. This energy was assumed to be deposited as a point source, Infinitely fast.

There have been several attempts to determine which characteristics of the spark discharge are important for ignition. The results of these experimental investigations have been rather confusing, and contrary results have been published at different times. For example, results indicating an optimal discharge time show a wide variation of such times.

As far as the IC engine designer is concerned, standard engineering practice has dictated that the spark be a low energy (10 $\mathrm{mJ}$ ), long duration (several $\mathrm{ms}$ ) discharge. The trial-and-erist engineering approach reasoned that a long discharge guaranteed ignition at some point and the low energy seemed to be what they could "get away with." This design approach falled when operating conditiuns moved away from the normal stolchiometric operating point, as in the move towards leanburning engines.

Extensive investigations on the influences of spark discharge characteristics on ignition have been carried out during the past two 
decades. Ballal and Lefebvre (1975) examined the effect of breakdown voltage, spark duration, energy deposition, gap width, electrode geometry, and electrode material in low pressure (sub-atmospheric) flowing gases.

Their results indicated that, for quiescent stolchlometric mixtures. minimum ignition energy was obtained for a discharge of $60 \mu \mathrm{s}$. Other results Indicated that higher minimum ignition energles are obtained with electrodes materials having higher bolling temperatures. Ballal and Lefebvre (1975) also obtalned results that would be expected on the basis of arc physics, namely that Pachen's Law (see for example Kuffel and Zaengl, 1984) was valid. It says that breakdown voltage is proportional to the product of pressure and gap length. and that the spark energy. Eg, Is:

$$
E \sim d_{g} \exp \left(\frac{P d_{g}}{\exp P}\right)
$$

where $d_{\mathfrak{g}}$ is gap length, and $P$ is the pressure. Thus, $E_{\mathcal{G}}$ is most sensitive to gap length.

Good progress towards understanding the physics of spark ignition has been contributed by Maly and his colleagues from the University of Stuttggart. They examined the complete discharge process with timeresolved interferometry and spectroscopic techniques. Their results would warm the hearts of most plasma physlcists. The distinct nature of breakdown, arc and glow phases of the discharge and the Importance of 
each phase to Ignition of combustible mixtures were first recognized by these Investigators.

The voltage and current characteristics of a discharge are shown schematically in Figure 4.1. The breakdown phase results in a rapid Ionization of the spark channel (diameter typically $10-40 \mu \mathrm{m}$ ), with peak currents of a few hundred amps for a period of 10-100 nsec. The fully Ionized channel has peak temperature of $\sim 6 \times 104$ OK. and the resulting high peak pressure produces a shock wave.

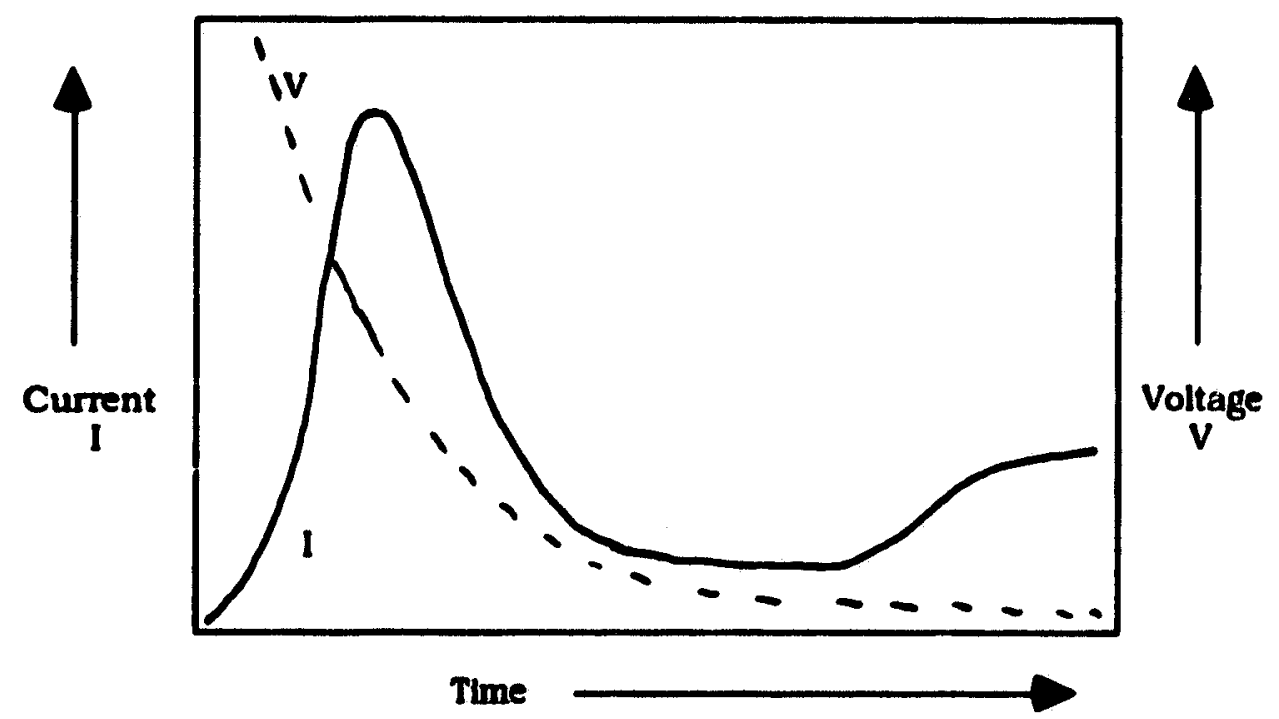

Figure 4.1 Discharge current and voltage characteristics

The arc phase is characterized by a lower sustaining voltage, $50-100 \mathrm{~V}$. the current is typically a few amps, and the duration is $10.100 \mu \mathrm{s}$. The arc continues to expand mainly due to conduction and diffusion. Heat loss, especially to the electrodes. limits the kernel to about $6 \times 10^{3} \mathrm{oK}$. In the glow phase, the current drops to $\sim 200 \mathrm{~mA}$, with a duration of 100 
$.1000 \mu \mathrm{sec}$; there is a high cathode fall of $300-500 \mathrm{~V}$; and the temperature drops to $3 \mathrm{X}: 0^{3} \mathrm{oK}$, resulting in a very low level of Ionization. The bulk of the discharge time of typical igniting systems is In the glow phase. Erosion of the electrodes takes place primarlly during the arc phase, more modestly during the glow phase, and negliglbly during the breakdown phase.

Maly and Vogel (1978) examined the spark kernel dynamics of each of the three phases and presented striking results that indicated the breakdown phase was important to the development of the spark kernel. The radial extent of the kernel develops very rapidly as the energy in the breakdown phase is enhanced. Experiments in a combustible mixture showed that the breakdown type of discharge (10-100 ns) was most effective, and that these types of discharges created a much larger kernel than arc or glow discharges of equivalent energies.

Maly (1981) developed a thermal model for these ultra fast discharges. The shell-like structure suggested by the measured temperature profiles, Indicated in Figure 4.2, is the basis for Maly's model. He assumes a radially symmetric geometry, constant pressure, and conduction as the only transport mechanism. The last assumption is taken into account by having laminar and turbulent heat fluxes lumped into a single transport coefficient kD. Maly's Ignition criterion is expressed as:

$$
\left(x q-\Delta H_{F}\right) P_{0} r_{1} \frac{d r_{1}}{d t}\left[2 R k_{D} T_{0}\left(T_{1}-T_{0}\right)\right]^{-1}=1
$$


where $x q$ is the molar heat of combustion. $\Delta H_{F}$ is the average molar enthalpy required to ralse the gas to the flame temperature. and $r_{l}$ and $d r_{1} / d t$ are the flame front position and velocity, respectively. This Ignition criterion is most notable due to the appearance of the velocity of the leading edge of the kernel, $d r_{1} / d t$. It presents first example of the dynamics of the spark kernel manificsting itself in the ignition process. Maly also derived expressions for the quenching distance and $\mathrm{m} / \mathrm{n} / \mathrm{mum}$ Ignition energy, but this calculation based on the dublous excess enthalpy assumption of Lewis and von Elbe.

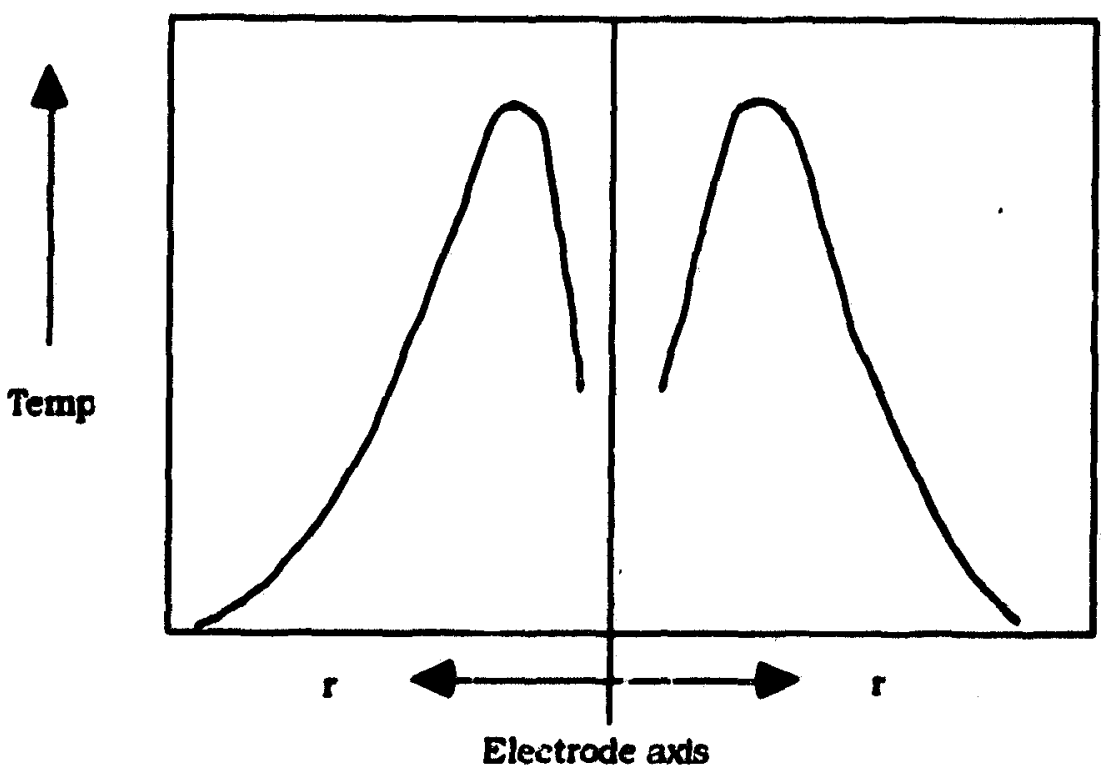

Figure 4.2 Measured temperature; ;rofle of a spark kernel, after Maly and Vogel (1978).

Zlegler et al. (1984) continued this Investigation Into the Ignition qualities of the arc and glow discharge phases. Thelr results - icate that energv dissipated in the anode and cathode fall is compls lly lost to the electrodes, whereas the energy in the positive column is what is 
effective for Ignition by predominantly arc or glow phase discharges. This observation was originally pointed out by Swett (1957), and the results are particularly important because most previous investigations that determined the $\boldsymbol{Q}_{\min }$ experimentally did so by measuring the spark gap voltage and current, and then computing $Q_{\min }$ by NIdt. Thus, the results of Ballal and Lefebvre and others uverestimate $Q_{\mathrm{min}}$, and it is Interesting that any orrelation with $\mathrm{d}_{\mathbf{q}}$ was possible.

\subsection{Time-Dependent Ignition Models}

Other workers have attacked the problem of spark ignition with the Idea of somehow Incorporating the time dependence of the spark energy input.

Aldeman (1981) calculated th : flow field behind the shock front produced by a discharge whose energy input is time dependent. The spherically symmetric model is notable because it is basically non-thermal, neglecting conduction as a loss mechanism. Unfortunately, his results would only compare well with data obieined by Lichfleld (1961) if he chose a spark Guration different from the experimental one.

The riumerical calculations of Dixon-Lewis and Shepard (1975) solved the time-dependent conservation equations, Incorporating multI-step reaction kinetics in both spherical and cylindrical coordinates, to eximine the growth of $\mathrm{H}_{2}$-air flames. Blast wave effects were ignored, however. The authors' results indicated that, for a constant total 
Ignition energy, flame initiation was enhance by increasing the proportion of energy supplied as $\mathrm{H}$ atoms rather than as thermal energy.

Similarly, Oran and Boris (1982) solved the same equations assuming spherical symmetry, but they used a complex 48 -step reaction mechanism to describe the kinetics. Their results are somewhat disappointing. given the complexdty of their model, as the ignition energy could not be computed with any accuracy.

Rafeal and Sher (1985) solved, numerically, the cylindrically symmetric conservation equations for methane-air mixtures at constant pressure. The radial profile of the time-dependent power input from the discharge was computed from the plasma conductivity given by Plooster (1979) and radiation losses where taken into account. The reaction kinetics were modelled by an 18-step mechanism. The breakdown energy of the discharge was used as an Initial condition. The results of Rafeal and Sher's (1985) calculations show clear maniliestations of combustion in the radial temperature profile as early as $10 \mu \mathrm{s}$ after the initlation of the discharge.

Akindele et al. (1982) solved the spherical symmetric conservation equations with turbulent transport coefficients. Their calculations Indicate ine trends observed In their experiments, but no quantitative results were obtained for $Q_{\mathrm{min}}$. 
4.4 Experimental Observations of Spark Kernels

In all the thermal theortes revlewed here, the basic geometrical structure for the spark kernel was spherical. The numertcal models assumed either spherical or axial symmetry. Suprisingly, experimental observations of the kernels produced by spark discharges, dating back to Olsen et al. (1952), have consistently shown a definite toroidal structure. This suggests that the mechanism involved in cietermining the underlying dynamics of spark kernels is responsible for this type of structure, and that it may be fundamental to the geometry of an axdal arc discharge.

The schlleren photographs taken by Kono et al. (1976) of kernels are most striking evidence of the toroidal structure that evolves after the discharge. Chomlak (1979) was the first to note this toroldal structure and he developed a phenomenological model of the spark kernel. He suggested that hydrodynamic effects are dominant in determining the evolution of spark kernels. His model suggested a circulation pattern that is very similar to that for the ignitton kernel model proposed for plasma jets by Topham et al. (1981). Plasma jets as Ignition sources have been revfewed by Clements (1984), and the plasma jet ignition model was presented by Topham et al. (1984).

We have obtained schlleren and shadowgraph Images of axlal spark kernels in air for a wide range of discharge conditions, using a high speed video camera and a laser diode light source. Figures 4.3 and $4.4 \mathrm{sh}-\mathrm{N}$ selected images from sequences taken of two similar discharges, viewed 
along and normal to the discharge axds, respectively. A distinctly toroldal structure with sharp boundaries is clearly visible in both sets of images. The major and minor axes of the torus expand in time and, at about $500-700 \mu \mathrm{s}$ after the beginning of the discharge, the structure becomes unstable. Figure 4.5 shows examples of single shadowgraph images of spark kernels produced by an electrical discharge of higher energy and longer discharge time-1.0 J stored energy, discharged over $150 \mu \mathrm{s}$. The kernel structure is again clearly toroldal, biat developed over much longer time scales than the spark kernels of Figure 4.4. The structure appears to remain well defined and laminar out to $11 \mathrm{~ms}$, the longest time interval imaged. Our results support the observations of Kono et al. (1976), which show a well-defined toroidal region of hot gases with a sharp boundary produced by axial discharges.

More evidence of a toroidal structure with a sharp boundary is provided by the temperature profles of axdal discharge spark kernel obtained by Maly and Vogel (1977). Akindele et al. (1982), Borghesse et a.l (1988), and Haley and Smy (1989). These results suggest that the toroldal structure is an inherient characteristic of the aftermath of an axial spark discharge.

Experimental efforts have shown that the temporal characteristics of the spark discharge are very important for ignition. In particular, the Initial spark gap breakdown energy is critical in spark kernel development. Other experiments clearly show that the kernel structure is markedly 
different from the traditional theoretical vlew of a spherical region Initiated by a point heat source.

In the next chapter. we develop a new model of spark kernel development that follows from the observations of the torotdal kernel structure. The energy dellvered to the spark gap produces hydrodynamic flows that result in the well-defined kernel structures observed. Links to plasma jet kernels are made. giving spark kernel development from electrical discharge sources a common physical thread.
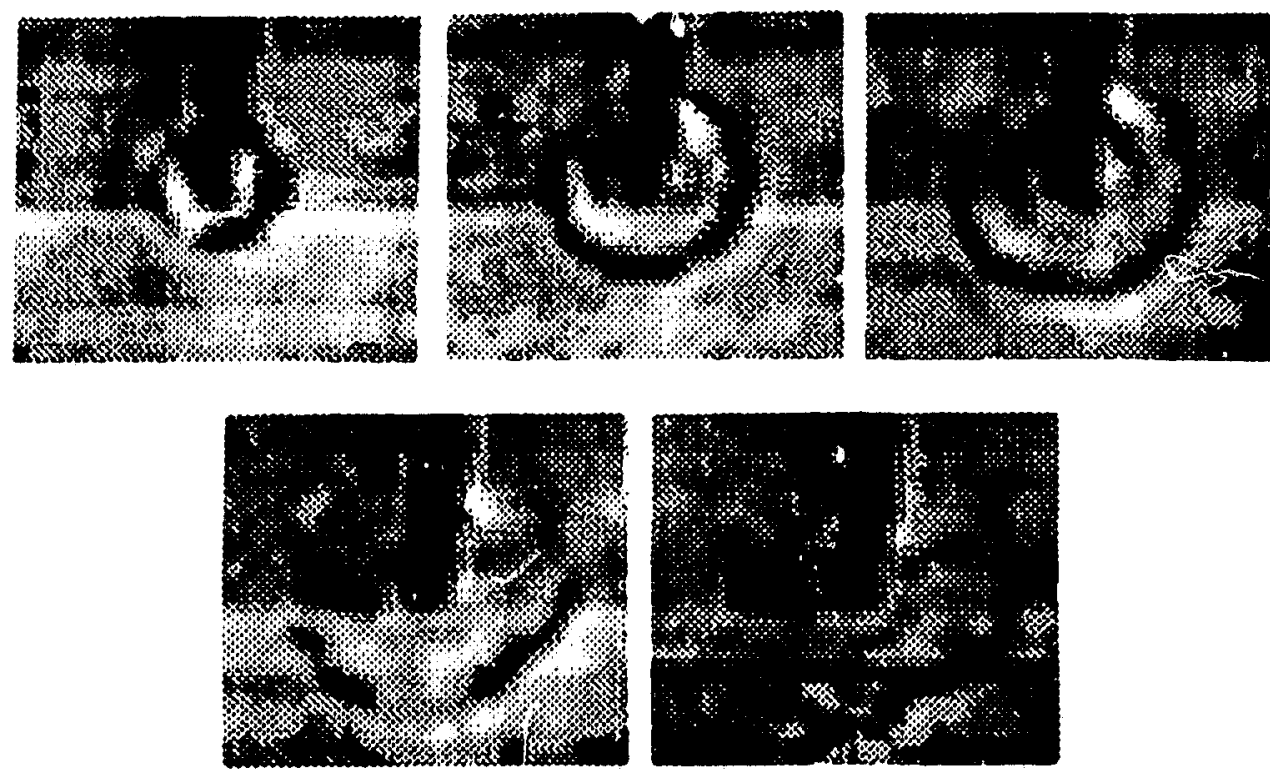

Figure 4.3 Schlleren Images of a spark discharge, vewed along the discharge axts. The Initlal frame is taken $91 \mu s$ after the discarge begins. The subsequent frames are $167 \mu \mathrm{s}$ apart and the $62 \mathrm{~mJ}$ discharge is $50 \% \mathrm{~s} \mathrm{long}$. 

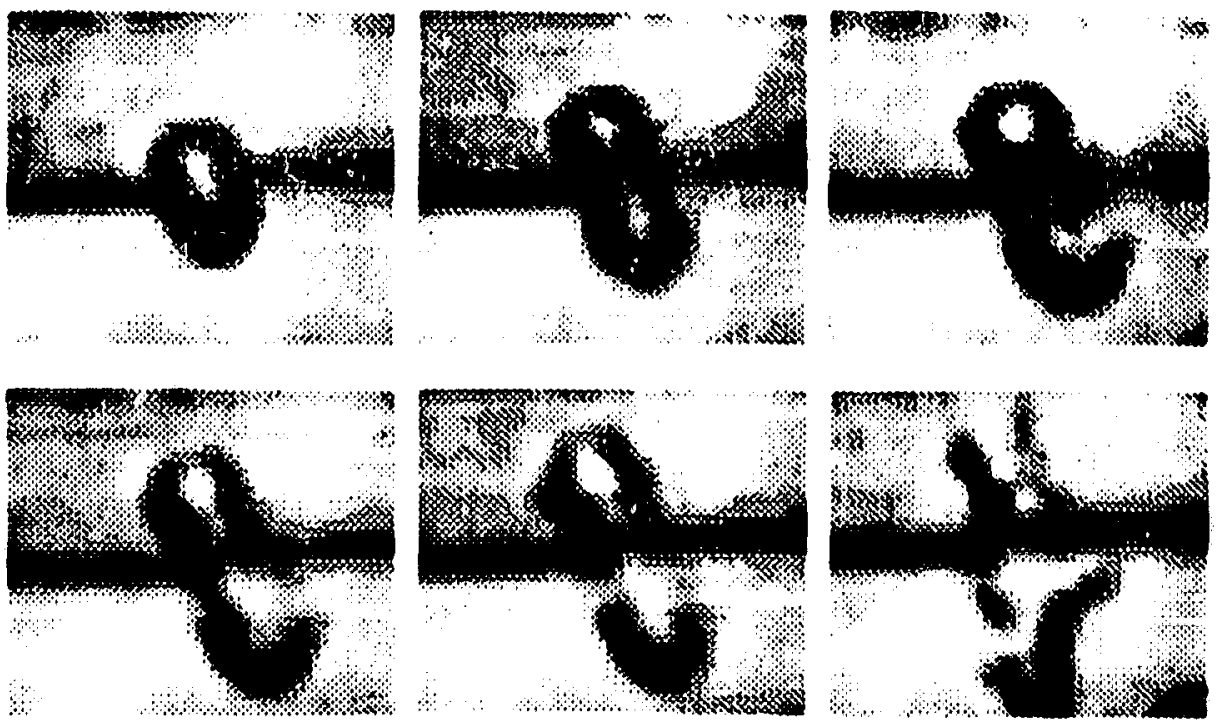

Figure 4.4 Schlieren images of spark discharge, vtewed normal to the discharge axds for the same discharge and frame times as Figure 4.3.
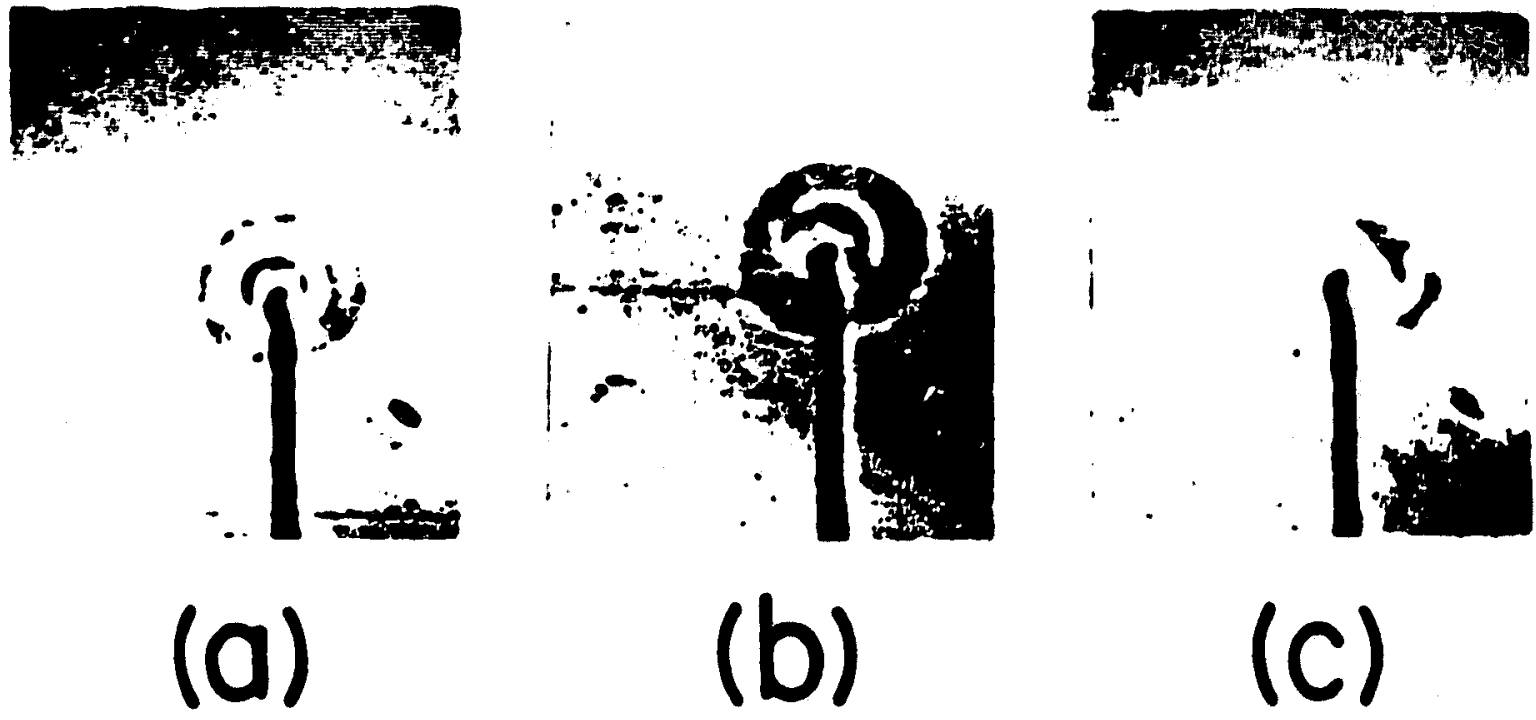

(c)

Figure 4.5 Shadowgraph Images of opark kernels; energy $1.0 \mathrm{~J}$. discharge time $150 \mu \mathrm{s}$. and frame times (a) $3 \mathrm{~ms}$, (b) $8 \mathrm{~ms}$, (c) 11 (ms) after the beginning of the discharge. 


\section{$5 \quad$ A Unified Approach to Spark Kernel Development: Mixing Models}

In this chapter we examine spark ignition by concentrating on the underlying fluid clynamics in the critical early phase of a spark kernel's development. From thls fluld dynamic point of view, we can then show how the basic ignition process is common to the major practical ignition sources. The materfal in this and the following chapters first appeared in Pitt et al. (1991), which can be found in Appendix I. Some differences in notation and scallng are used.

The prevlous chapter showed clearly that the conventional view of a simple point heat source, diffusion model of ignition falls to predict the observed spark kernel structure. If we go further and include the major practical Ignition devices discussed in Chapter 2, we have, from our literature, a plcture of igniton that looks like that shown in Table 5.1.

\begin{tabular}{|c|c|}
\hline Ioniter type & Model \\
\hline Plasma jet & $\begin{array}{l}\text { Exottc radicals (Orrin et al.1981): } \\
\text { turbulent mixing elements (Topham et al. } \\
\text { 1984) }\end{array}$ \\
\hline Puff jet & $\begin{array}{l}\text { Turbulent mixdng elements (Pitt et al. } \\
\text { 1983) }\end{array}$ \\
\hline Conventional axdal discharge & $\begin{array}{l}\text { Thermal diffusion (Ballal and Lefebvre } \\
\text { 1975, Ko et al. (1991a) }\end{array}$ \\
\hline Surface discharge & No models, some experimental data \\
\hline Fast discharge & $\begin{array}{l}\text { Modifed thermal model (Maly and Vogel } \\
\text { 1978) }\end{array}$ \\
\hline
\end{tabular}


Of the five practical devices in Table 5.1. only the plasma jet and puff jet are related by a common physical mechanism-hydrodynamic mixing. The remaining sources appear to be unrelated to the first two.

This chapter establishes the basls for a new point of view of spark Ignition. The spark kernel is to be vlewed as a distinct entity - a fluid element with distinct dynamic properties. From this point of view, a classification scheme is proposed that will group the practical ignition sources of Table 5.1 into two classes, based on either the spherical or toroldal symmetry of the spark kernel produced. Toroldal mixing elements are discussed in some detall, and then. in Section 5.4, a toroldal element mixing model is developed. In the final sections of the chapter, we compare observed spark kernel behaviour with the model presented and speculate on a possible mechanism to generate the necessary flow.

\subsection{Underlying Dynamics of Spark Kernels}

The observations described in the preceding chapter revealed an important characterlstic of spark kernels from axjal discharges: the existence of toroldial flutd structure with sharp boundarles. Much of the experimental evidence, then, does not support the conventional model of a point heat source creating, solely by diffusive processes, a spherically symmetrtc region with an exponentlally decreasing radial temperature profile.

Figure 5.1 compares the temperature profiles and morphology predicted by the bastc thermal model and experimental observations. The Internal flow 
necessary for the observed toroldal structure of kernels suggests that mechanisms such as entrainment and vortex dynamics play an essential role in the early evolution of spark kernels. This means that spark kernels produced by axdal discharges belong to a class of self-propagating freemixdng elements governed by hydrodynamic flows. They therefore have certain features in common with the kernels produced by plasma jet and surface discharge devices. Thts common thread of fluid dynamics provides a basis for classifying various igniter types as is done in the next section. 


\section{Temperature Profile}
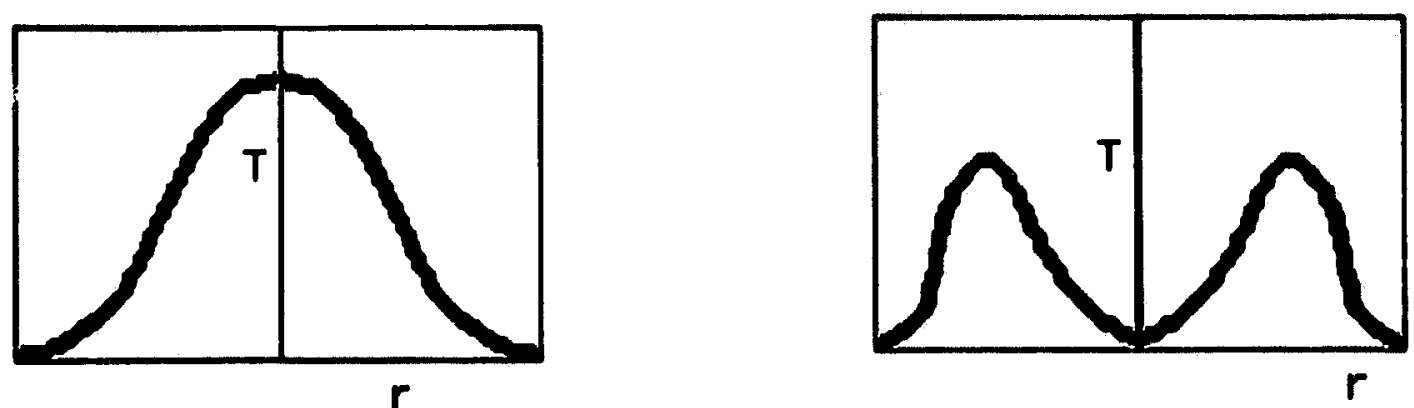

Morphology

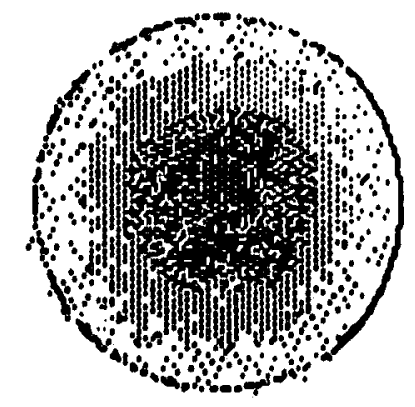

\section{View along discharge axis}
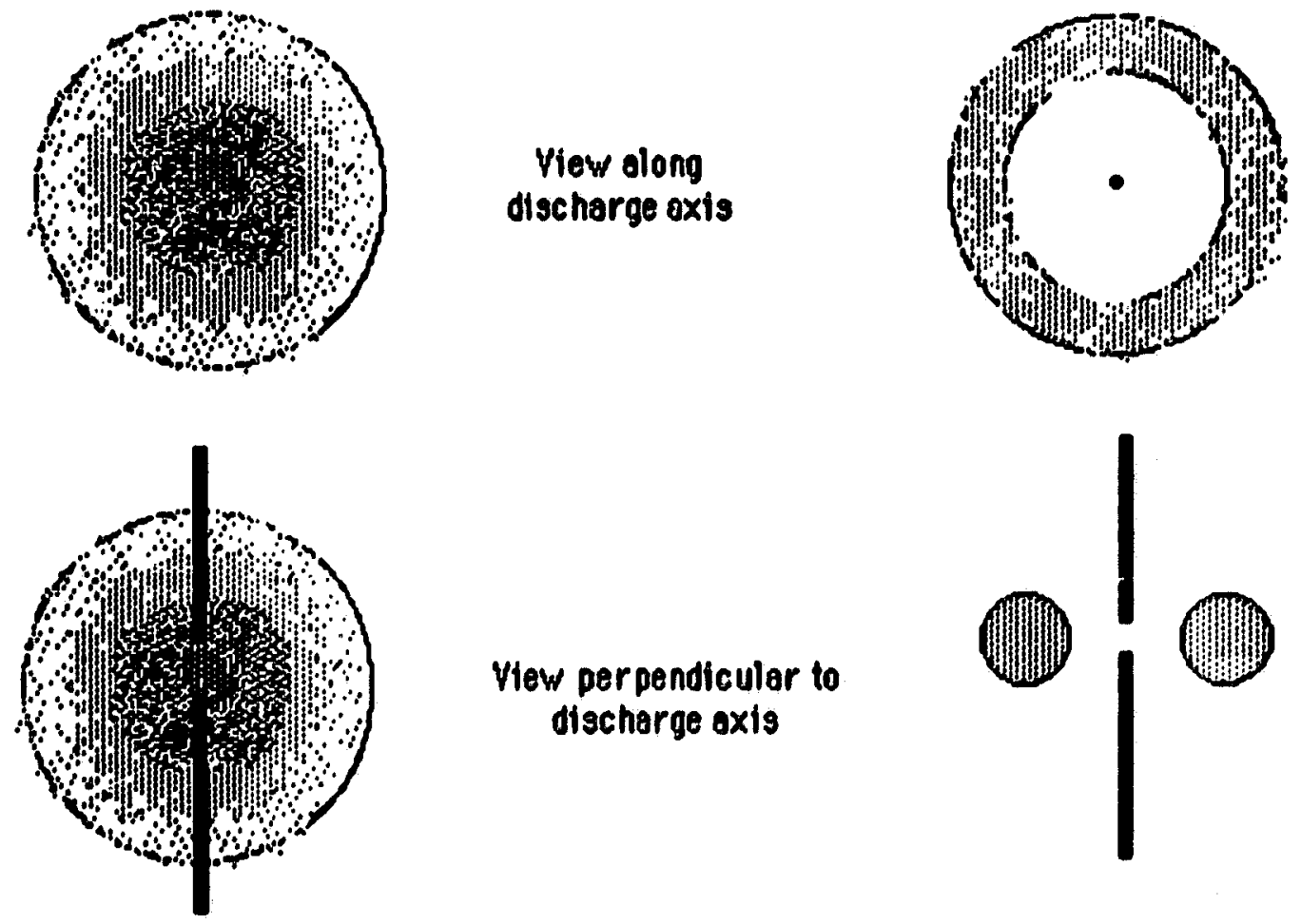

View perpendicular to discherge axis

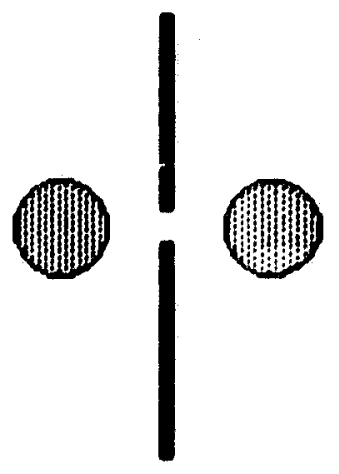

Figure 5.1 Basic thermal model features and experimental observations. 
6.2 Proposed Classiffcation of Ignition Sources

Ignition sources used in most electrical discharge Ignition systems are of three bastc types. characterked by the geometry ci the electrodes forming the spark gap of the ignittion source. The three source types-axtal discharge, surface discharge, and plasma jet-are shown schematically in Figure 5.2.

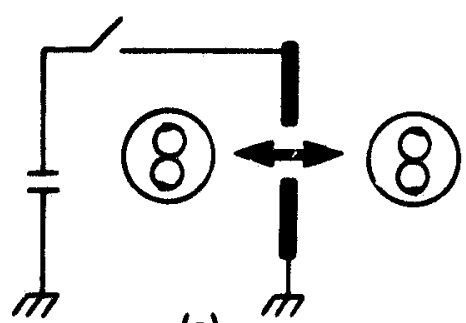

(a)

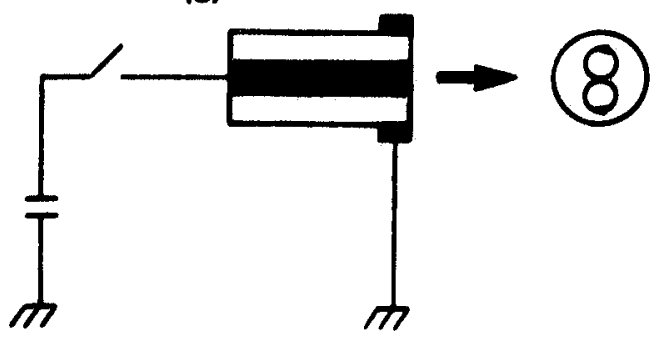

(b)

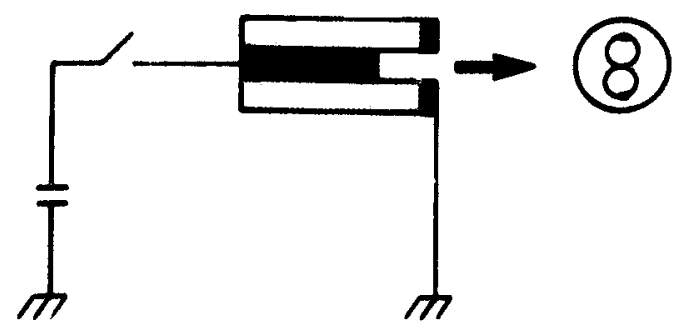

(c)

Figure 5.2 Baslc igniter types showing Imparted momentum (arrows) and corresponding flow patterns: a) axtal discharge, b) surface dtocharge, c) plasma jet.

We propose a classification scheme for these Ignition devices to link the basic physical processes that govern the dev 'opment of the spark kernels produced by axdal dissharges, surface discharges, plasma jet discharges. and puff jets. It is not only the energy which is important for the 
establishment of ignition, but also the manner by which it is supplied. This latter aspect leads to the classification scheme that differentiates between ignition sources on the basis of the energy, impulse, and initial vorticity distribution Imparted to the spark kernel.

Experimental observations of kernels produced by plasma jet sources suggest that the kernels resemble fluid structures similar to atmospheric thermals (Topham et al. 1982). Measurements of the momentum Imparted to the hot gases expelled by such sources have been reported (Smy et al. 1985). Ignition kernels produced by surface discharge sources have not recelved much attention. However, schileren Imagery (Bradiley and Critchley 1974) indicates that the morphology of surface discharge kernels is similar to that of plasma jet kernels. Also. the niomentum imparted to surface discharge kernels has been measured (Smy et al. 1985) and was found to be les, than that for a plasma jet source using the same discharge current.

A model describing the evolution of spherical turbulent mixing elements (spark ke:nels) produced by plasma jets is well established (Topham et al. 1984). This model lllustrates the role that momentum, Imparted to the spark kernel, plays. Figure 5.2 indicates the axially directed momentum of spherical spark kernels and the basic circulation pattern. The Initial hot kernel expelled by the plasma jet begins to entrain a cooler, amblent mixture as the kernel propagates away from the plasma jet exIt. For a given discharge energy, plasma jet kernels with higher Imparted momentum mix and dilute more rapidly. 
The turbulent spherical mixing element model has been extended to Include a simple Arrhenius type of heat addition term, to simulate combustion in an element propagating into a combustible mixture (Topham et al. 1986). In thls case, the introduction of a cold mixture into the interior of the element acts to control the rate of heat release by chemical reactions. The model solutions divide into two distinct types: those for which the mean density finally approaches the ambient level. termed the "extinction branch": and those for which the density rapidly attains a low value which is maintained at a constant level. This selfsustalning, high temperature state is called the "combusting branch." Ignition criterla based on thls model are discussed in the next chapter.

The puff Jet Ignition source of Chapter 2 user the spherical turbulent mixing element model to predict where and when a small turbulent puff of methane would mix and dilute to near stolchiometric conditions sultable for easy spark Ignition (Pitt et al. 1984). This ignition source is clearly related to plasma jet Ignition kernels through a common physical process.

Surface discharge spark kernels, as noted previously, appear to be simllar to plasma jet kernels, but have lower imparted momentum. Although no data are avallable to compare these kernels to the sipherical iurbulent mixing element model. we propose that these kernels should belong to this class of mixing elements. 
In the case of the axdal discharges, such as conventional ignition sources or fast discharges, the observed toroldal nature of the spark kernels produced suggests that the momentum imparted to the toroldal kernel is radially directed, as shown in Figure 5.2, where the circulation pattern is also Indicated.

We propose that there are two main classes of fluld flow assoclated with the momentum imparted to a spark kernel. First. there is the axlally directed momentum imparted by plasma jets, surface discharge, and puff jets, which create spherically symmetric mixing elements. Second, th. re is the radially directed momentum imparted by axdal discharges of elther conventional or fast discharge types, which create toroldal mixing elements. We suggest differentiating the two classes of Ignition sources by the morphology of their resulting spark kernels. Spark kernel3 produced would then be of either the spherical or toroldal class.

Regardless of the class, all spark kernels evolve according to similar hydrodynamic mixing processes involving entrainment and vortex dynamics. Not only is the energy imparted to the element important, so is the momentum.

The ignition sources of Table 5.1 can now be rearranged according to the two main classes of spark kernels produced (Table 5.2).

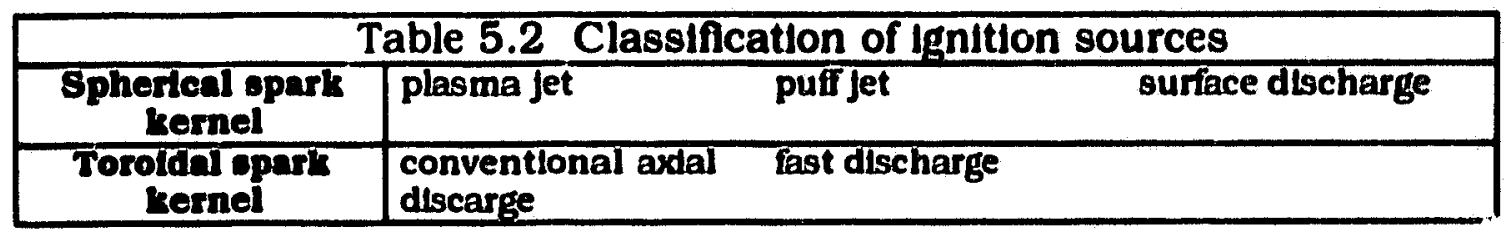




\subsection{Toroidal Mixing Elements}

Having linked the basic physical processes underlying the development of spark kernels from plasma jets to those produced from axdal discharges. we still must face the problem of developing a suitable model for the toroldal mixing elements. The fluid mechanics of the toroldal flow is considerably more complicated thian that assumed for the self-similar entraining spher!cal elements to model plasma jet kernels.

Our model assumes that the toroldal element contains the double circulation pattern first suggested by Chomiak (1979) and shown in Figure 5.2. As the torus expands radially, the internal vorticity fleld stretches, which in turn influences the radial expansion velocity of the element Itself. In addition. the small physical size of the elements results in low Keynolds riumber flows for which molecular diffusion can be uaportant. In general, the effects of molecular diffusion, combined with the rapid adjustment forced on the internal flows by the stretching, precludes the simple similarity assumption by Maxworthy (1972) and later by Chomiak (1979) to understand the hydrodynamics of spark kernels. 


\subsection{Toroidal Mixing Model: Non-combusting} Solutions

We now develop a model to examine the behavtour of toroldal spark kernels. The first step is to model the non-combusting case. This would be applicable to experiments Involving spark kernels in air. In the next chapter, we extend the model to combustible mixtures.

Our model is an extension of the spherical mixing model applied to pla sma jets by Tophan et al. (1984), which Itself was an adaptation of an atmospheric thermal model. The foundation of the model is that the entrainment assumption of Morton et al. (1956) is applicable. This requires the following assumptions:

- there is no loss of momentum or heat from the element to a wake;

- the mixing element has a toroidal shape with uniformly distributed properties:

- the mixing takes place at constant pressure;

- the mixing element and amblent environment are perfect gases:

- ambient fluid is entrained into the element at a rate proportional to its velocity and surface area. The constant of proportionality, $a$, is fired for a given mixing eiement, but can vary from one element to another. 
63

Figure 5.3 shows the toroldal coordinates, $r$ and $b$, respectively the major and minor axes of the mixing element. In this orlentation, the spark electrodes lie along the b-axis.

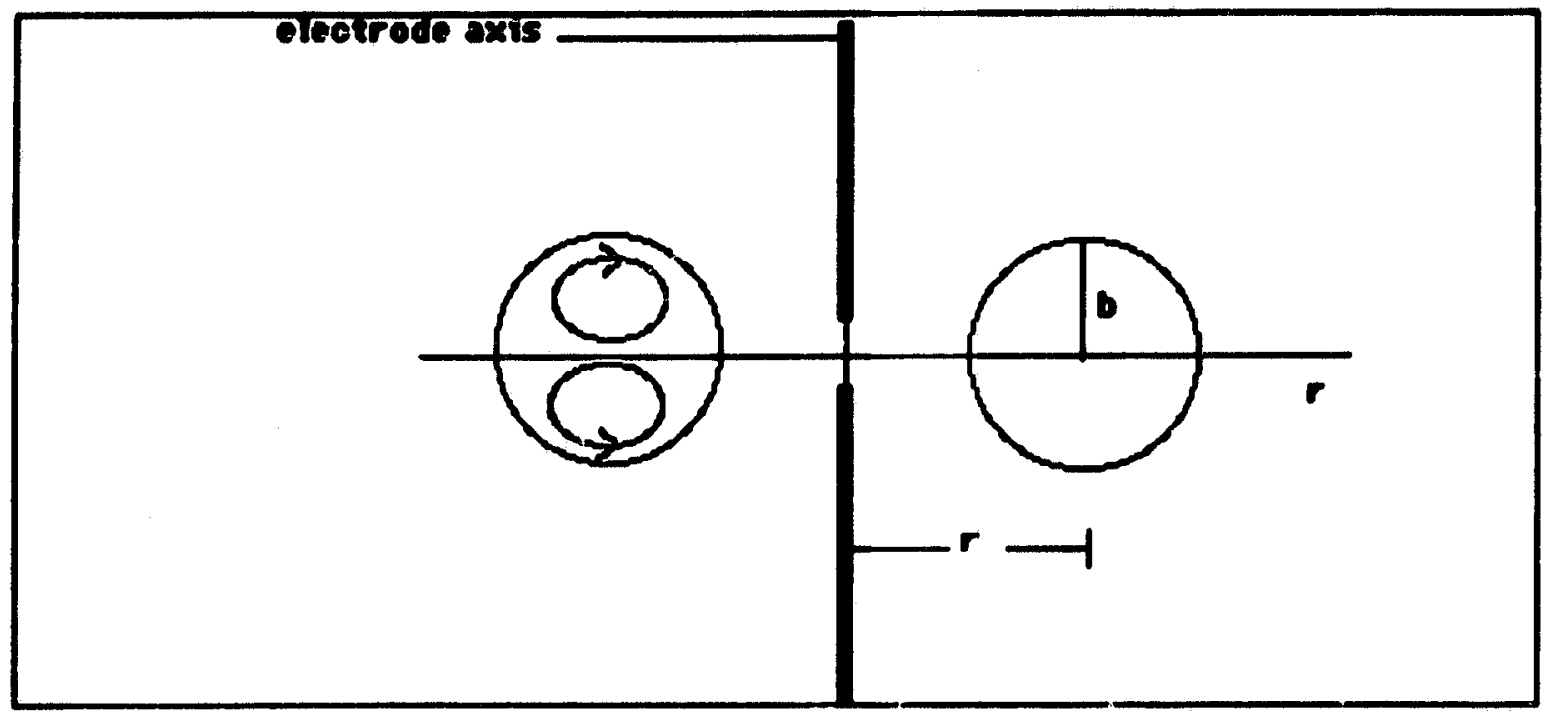

Figure 5.3 Toroldal ccordinate system

The basic conservation equations are then:

Mass:

$$
\frac{d}{d t}\left(2 \pi^{2} r b^{2} \rho\right)-a 4 \pi^{2} \rho_{0} r b \frac{d r}{d t}
$$

Momentum:

$$
2 \pi^{2} r b^{2}\left(\rho+k \rho_{0}\right) v=I_{0}
$$

Energy:

$$
2 \pi^{2} r b^{2} \rho\left(h-h_{0}\right)-H_{0}
$$

Radial velocity: 


$$
v=\frac{d r}{d t}
$$

where the initial conditions are:

$$
\begin{aligned}
& \beta=\frac{\rho}{\rho_{0}}-0 \\
& b=b_{0} \\
& r=r_{0}
\end{aligned}
$$

It is convenient to find scaling quantitles that will put the conservation equations Into non-dimensional form. The initial conditions (5.5) provide such quantities. From the energy equation, (5.3), we get, at $t=0$ :

$$
r_{0} b_{11}^{2}=\frac{H_{0}}{2 \pi^{2} \rho_{0} h_{0}}
$$

We now ciloose the following scale lengths for the coordinates:

$$
\begin{aligned}
& r^{\cdot}=\frac{r}{r_{0}} \\
& b^{-}=\frac{b}{b_{0}}
\end{aligned}
$$

where ro and bo must satisfy (5.6).

The momentum equation, (5.2), gives, at $t=0$ :

$$
r_{0} b_{0}^{2} k\left(\frac{d r}{d l}\right)_{1=0}-\frac{l_{0}}{2 \pi^{2} \rho_{0}}
$$


whtch leads us to choose as the velocity scale:

$$
v_{0}=\frac{l_{0}}{r_{0} b_{0}^{2} 2 \pi^{2} \rho_{0}}-\left(\frac{h_{0}}{H_{0}}\right) l_{0}
$$

For scallng the time, we choose:

$$
\begin{aligned}
& t_{m}=\text { (radial scale length }) /(\text { radial velocity scale) } \\
&-\frac{r_{0} H_{0}}{h_{0} I_{0}}
\end{aligned}
$$

\begin{tabular}{|l|r|r|r|r|r|}
\hline \multicolumn{7}{|c|}{ Table 5.3 Scaling Quantities } \\
\hline & $\begin{array}{l}\text { Minor } \\
\text { ractius }\end{array}$ & $\begin{array}{l}\text { Major } \\
\text { radius }\end{array}$ & Velocity & Time & Density \\
\hline $\begin{array}{l}\text { Scale } \\
\text { length }\end{array}$ & $\mathrm{b}_{0}$ & $\mathrm{r}_{0}$ & $\mathrm{v}_{0}$ & $\mathrm{t}_{\mathrm{m}}$ & $\rho_{0}$ \\
\hline $\begin{array}{l}\text { Scaled } \\
\text { coordinate }\end{array}$ & $\mathrm{b}^{*}=\mathrm{b} / \mathrm{b}_{0}$ & $\mathrm{r}^{\circ}=\mathrm{r} / \mathrm{r}_{0}$ & $\mathrm{v}^{\circ}=\mathrm{v} / \mathrm{v}_{0}$ & $\mathrm{t}^{*}=\mathrm{t} / \mathrm{t}_{\mathrm{m}}$ & $\beta=\frac{\rho}{\rho_{0}}$ \\
\hline $\begin{array}{l}\text { Initial } \\
\text { conditions }\end{array}$ & $\mathrm{b}^{\circ}=1$ & $\mathrm{r}^{*}=1$ & $\mathrm{v}^{\circ}=1 / \mathrm{k}$ & $\mathrm{t}^{*}=0$ & $\beta=0$ \\
\hline
\end{tabular}

With the scaling quantities from Ta:lle 5.3, the normalized form of the conservation equations are:

$$
\begin{aligned}
& \frac{d}{d t^{0}}\left(\beta r^{\circ} b^{02}\right)=2 a \frac{r_{0}}{b_{0}} r^{\circ} b^{\circ} \frac{d r^{\circ}}{d t^{\circ}} \\
& r^{\circ} b^{\cdot 2}(\beta+k) \frac{d r^{\bullet}}{d t^{+}}=1 \\
& r^{02}(1-\beta)-1
\end{aligned}
$$


The solution of these scaled equations is straightforward and the detalls can be found in Appendix II. Soluttons of equations (5.11) to (5.13). which also satisfy the initial conditions (5.5), are:

$$
\begin{aligned}
& b^{\prime}-\Psi r^{\circ}+(1-\Psi) r^{\cdot-\frac{1}{2}} \\
& x=\Psi^{2}\left(r^{3}-1\right)+2 \Psi(1-\Psi)\left(r^{\circ \frac{3}{2}}-1\right) \\
& i=\frac{1}{4}(1+k) \Psi^{2}\left(r^{\cdot 4}-1\right)+\frac{4}{5} \Psi(1+k)(1-\Psi)\left(r^{-\frac{5}{2}}-1\right)+ \\
& +\{k-(1+k) \Psi(2-\Psi)\}\left(r^{\cdot}-1\right)
\end{aligned}
$$

where

$$
\begin{aligned}
& \Psi=\frac{2}{3} a \frac{\gamma_{0}}{b_{0}} \\
& x=\frac{\beta}{1-\beta}
\end{aligned}
$$

Figures 5.4a $-5.4 \mathrm{c}$ show the behaviour of the non combusting toroldal element solutions. where the numbers shown adjacent to each plot denote a different value of the parameter $\Psi$. The quartic asymptotic behavtour of the $r^{*}$ vs $t^{*}$ solution is very similar to that in the spherical element case. This is not surprising, as the basic conservation equations are functionally very simtlar. In the next section, we compare these solutions to observations of toroldal spark kernels. 


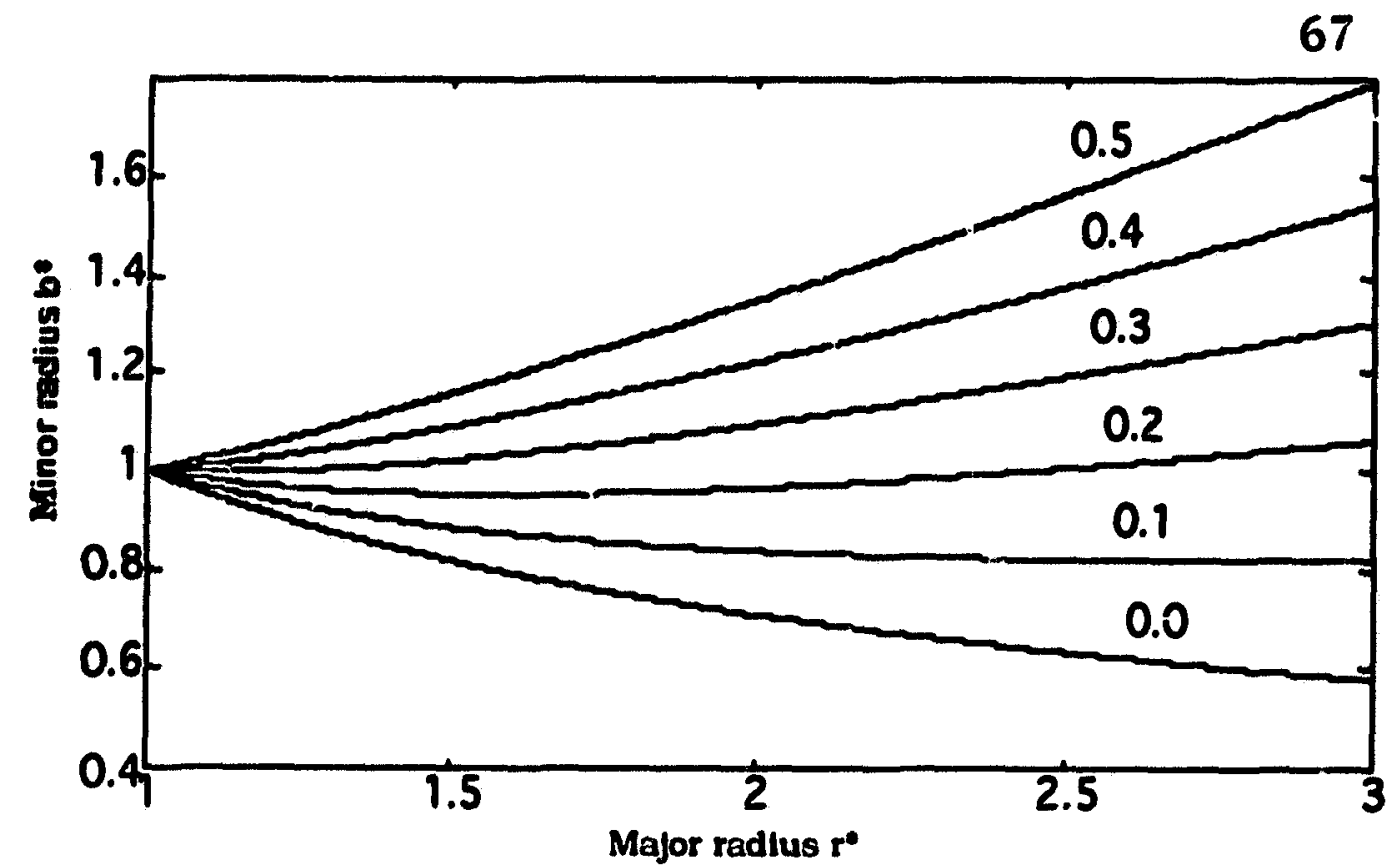

Figure 5.4a. Non-combusting model: equation 5.14. Numbers adjacent each plot denote the value of $\Psi$.

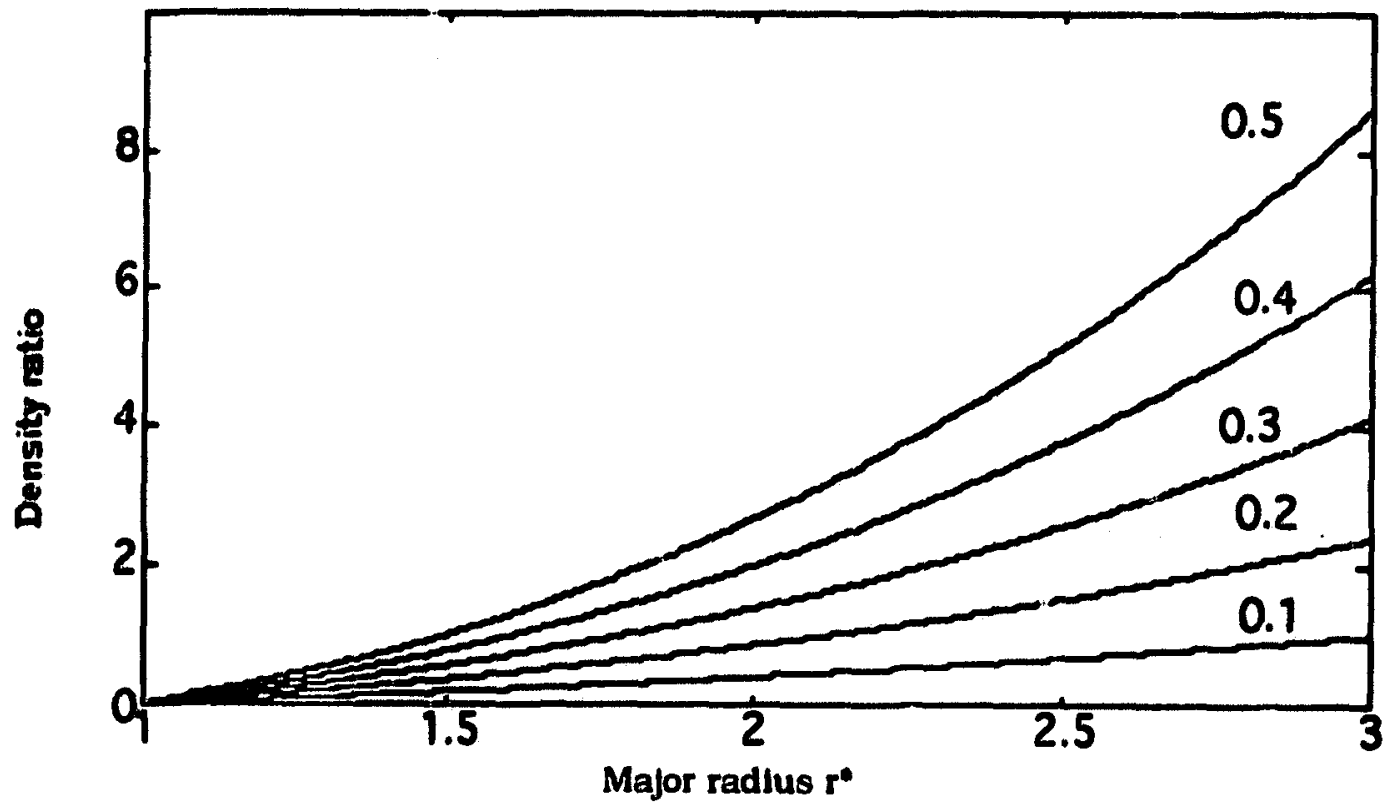

Figure 5.4b. Non-combusting model; equation 5.15. Numbers adjacent each plot denote the value of $\boldsymbol{\Psi}$. 
68

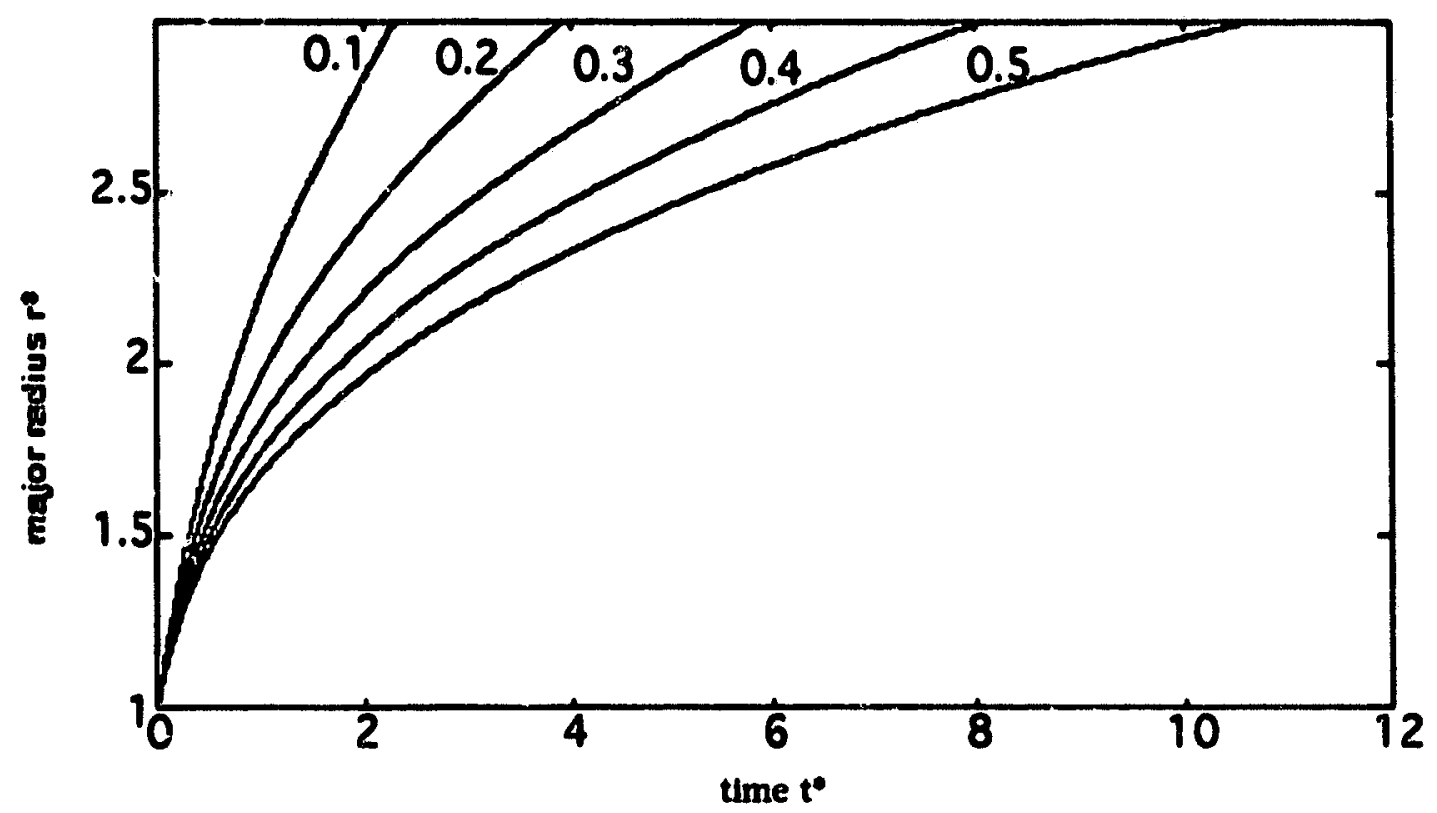

Figure 5.4c. Non-combusting model; equation 5.16. Numbers adjacent each plot denote the value of $\Psi$.

5.3

Comparison of the Toroidal Mixing Model with Observed Kernel Behaviour

The behaviour of sphertcal spark kernels produced by plasma jets has been Interpreted by a turbulent mixing model (Topham et al. 1984). The fit to the model solutions was good. The muxing model was further confirmed by Soloman (1988).

In contrast. fittin itata to the toroldal element model solutions is made more difficult because of our lack of knowledge of both the entralnment rate constant, $a$, and the ratio of the Initjal major and m/nor radil, $\mathrm{ro}_{0} / \mathrm{b}_{0}$. In the spherical case, measurement of the element radius as a function of propagation distance ylelds a value for the entrainment constant. For the 
toroldal case, simultaneously fitting data to equations (5.14) and (5.16) ytelds sultable values for $a$ and ro/bo.

We now look at some examples of kernel behaviour and compare these with the model just described. In general, published data on kernel morphology lack accurate measurement of the energy deposited into the electrode gap. Usually recorded is the stored energy avallable to the whole discharge circuit. Portions of the energy dissipated in other circuit elements must be accounted for. Furthermore, the momentum imparted to the gas is not normally measured, both because the measurement is difficult and the diffusion-based theorles have no need for it. However, Haley and Smy (1989) provide estimates of the momentum of radially expanding kernels as a function of energy. discharge time, and gap length.

The frst candidate for comparison. which we will call Example 1, is the spark kernel data from Figure 4.4 in Chapter 4. The second candidate, to be called Example 2, is from data published by Maly and Vogel (1978). The parameters that were used to scale the data are shown in Table 5.4. The momentum values are estImates from Haley and Smy (1989).

Examples 1 and 2 are compared to the non-combusting torotdal mixing theory in Figures 5.5a, 5.5b, and 5.6, respectively, where agaln the numbers adjacent to each plot denote values of the parameter $\Psi$. For Example 2, data for $b *$ vo $r *$ were not avallable. 


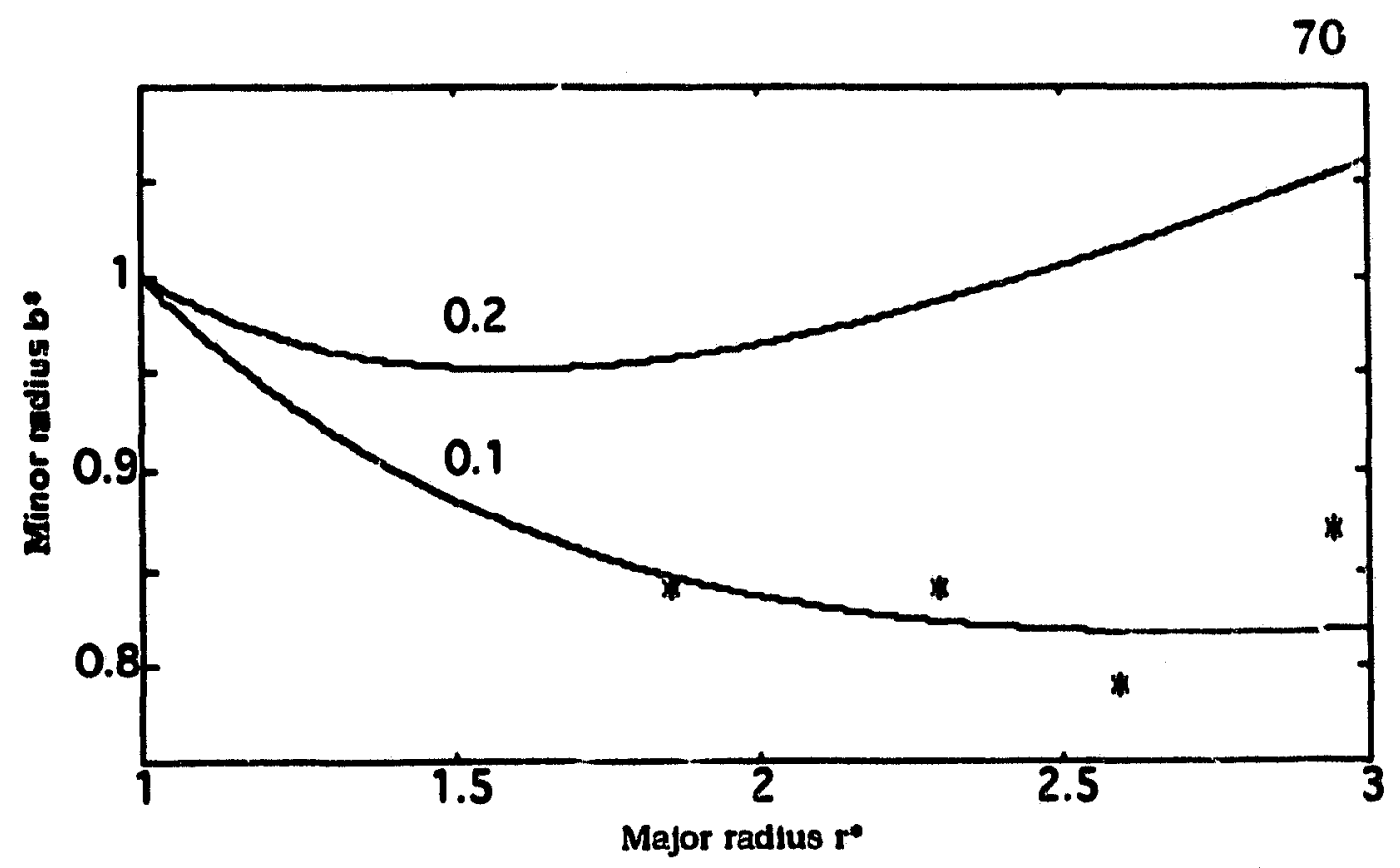

Figure 5.5a. Example 1 data $\left({ }^{\circ}\right)$ and the non-combusting model; equation 5.14. Numbers adjacent each plot denote the value of $\Psi$.

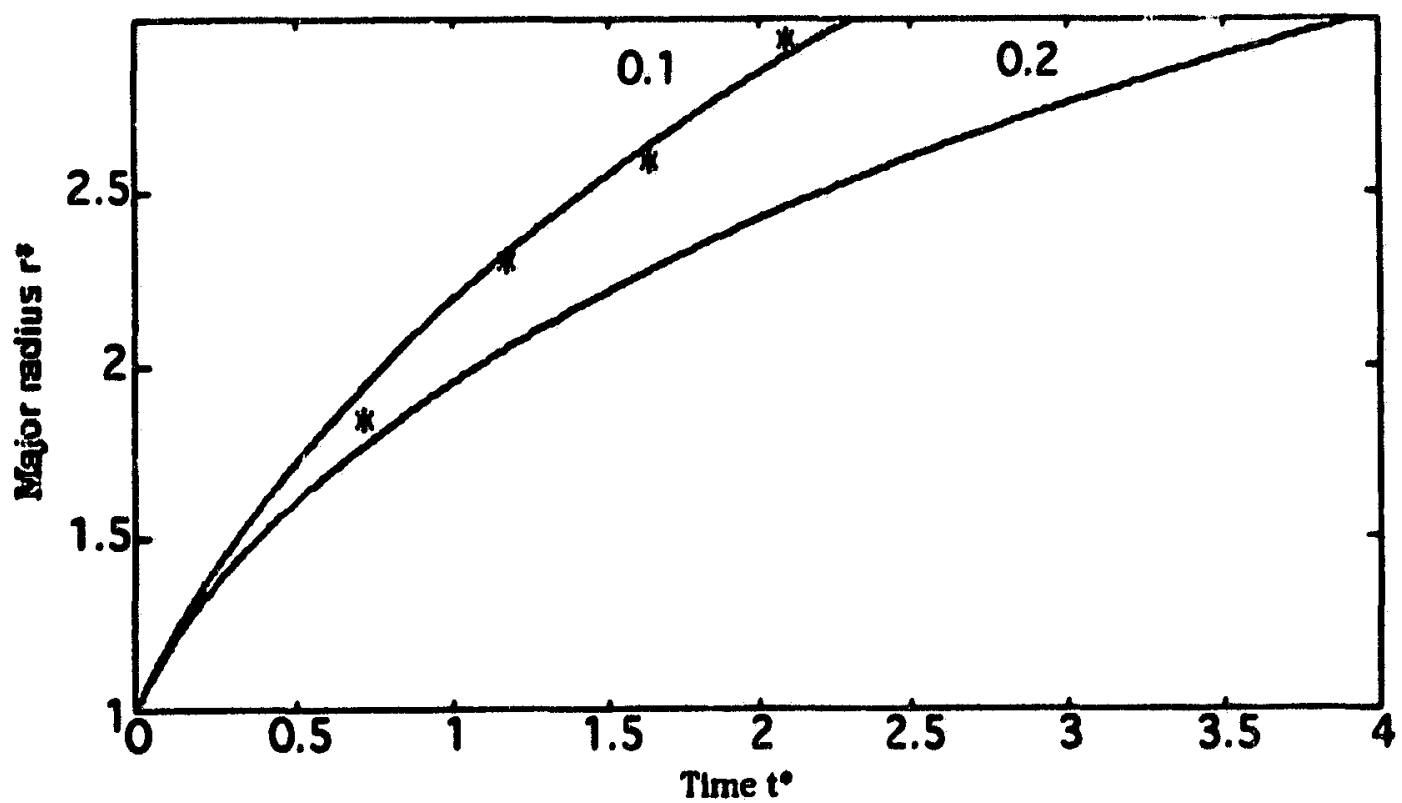

Figure 5.5b. Example 1 data ( $\left.{ }^{\circ}\right)$ and the non-combusting model; equation 5.16. Numbers adjacent each plot denote the value of $\Psi$. 


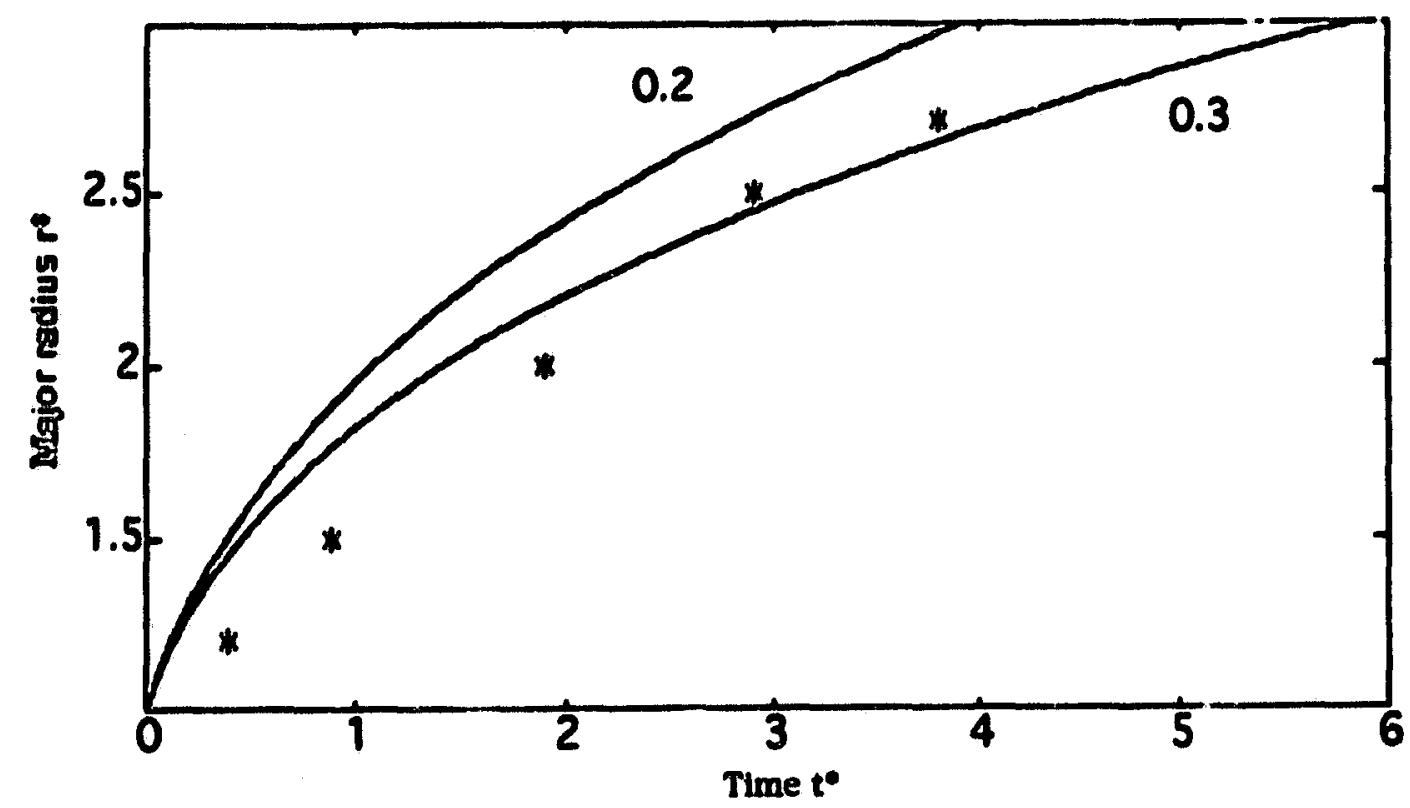

Figure 6.6. Example 2 data (") and the non-combusting model; equation 5.14. Numbers adjacent each plot denote the value of $\Psi$.

\begin{tabular}{|c|c|c|}
\hline & \multicolumn{3}{|c|}{ Table 5.4 Scallng data } \\
\hline Example & Ho $(\mathrm{m} \boldsymbol{)})$ & Io $(\mathrm{kgm} / \mathrm{sec})$ \\
\hline 1 & 5 & $2.4 \times 10^{-7}$ \\
2 & 30 & $6 \times 10^{-7}$ \\
\hline
\end{tabular}

The results are buth encouraging and puzzling. First, the coherent toroidal structures of Figure 4.4 resemble laminar vortex rings, at least before the onset of the observed instabllity. This suggests that a modification of the laminar vortex ring theory of Maxworthy (1972) would be more appropriate rather than the turbulent mixing model just presented. However, the simple entrainment assumption appears to be applicable. A possible explanation is that for these colherent structures, the entrainment is dominated by a single, large-scale circulation pattern 
of the type demonstrated by the flow visualizations of Haley and Smy (1989). If the kinetic energy remalns in this scale. Its distribution being unchanged elther by molecular diffusion or by transport to smaller scales over the time of Interest, the self-similar scaling Implled by the entralnment assumption may still hold.

Second, the data of Maley and Vogel (1978), used as Example 2, are compared to the non-combusting mixing model even though the data were obtained in a combustible mixture. Reasons for using the noncombusting model in this case are discussed in the next chapter. Even though the data for the non-combusting case are sparse and far from conclusive, the results are encouraging. given the uncertainties involved in determining the values of the energy and especially the momentum imparted to the elements.

\subsection{Mechanism ior Generating the Toroidal Flow pield}

It is interesting to consider a mechanism that could result in the types of circulation patterns suggested by the toroldal structure of spark kernels. Chomiak (1979) considered magneto-hydrodynamic forces to be important In establishing counter flowing axial jets that ccllide in the mid-gap region, resulting in a net radial flow with counter rotating vortices. However, estimates of the mhd forces Indicates that they are dominated by temperature and pressure gradlents. 
Kono et al. (1988) and Haley and Smy (1989) suggest that the transition of the shock wave from an initial cylindrical configuration to its final spherical form imparts the observed momentum to the kernel fluid. Vorticity is generated by the cross products of density and pressure gradients. Perhaps a spherically symmetric pressure teld in the wake of the shock, together with the predominantly cyllndrically symmetric temperature fleld of the InIttally hot gas kernel, is enough to generate the observed structures. Borghese et al. (1988) use similar hydrodynamic arguments, but suggest it is the high degree of curvature of the temperature and velocity fields near the electrode tips that is responsible for generating the required vorticity.

In the next chapter, we extend the toroldal model to combustible mixtures. We explore some of the model behaviour, discuss ignition criterla in light of the mixing element point of vtew, and examine mixing elements in turbulent ambient conditions. 


\section{A Unified Approach to Spark Kernel Development: Combustible Mixtures}

In the prevlous we chapter presented a mixdng model describing the evolution of a toroidal spark kernel in a non-combusting environment. We now extend the model to a combustible mixture by following the example of the spherical mixing element solutions in combustible mixtures provided by Topham et al. (1986). This model predtcted kernel behaviour remarkably well, the most striking result being the existence of two distinct classes of model solutions. In one class, the "extinction branch", are solutions that resemble the non-combusting solutions, where the density approaches the amblent level. In the second class, the solutions attain a low derisity, corresponding to a high bulk temperature which is malntained at a constant level. This self-sustaining, hightemperature state is referred to as the "combusting branch."

Section 6.1 below, we extend the toroldal mixing model to combustible mixtures by Including a simple Arrhenlus type of heat addition term to simulate combustion in an element propagating into a combustible mixture.

\subsection{Toroidal Mixing Model with Heat Addition}

In the non-combusting case, mixing caused the element's density to rise to the amblent level. In the combusting case, the cold, amblent mixture is introduced into the interior of the element by entrainment, and this 
acts to control the rate of heat release. To examine the behaviour of the coinbusting case, we modify the conservation equations of Section 5.4 to Include heat input in the energy equation, and add a reactant concentration rate equation. The equations are:

Mass:

$$
\frac{d}{d l}\left(2 \pi^{2} r b^{2} \rho\right)=a 4 \pi^{2} \rho_{0} r b \frac{d r}{d l}
$$

Momentum:

$$
2 \pi^{2} r b^{2}\left(\rho+k \rho_{0}\right) \frac{d r}{d t}=l_{0}
$$

Energy:

$$
\frac{d}{d l}\left(r b^{2} \rho\left(h-h_{0}\right)\right)=r b^{2} q k c^{2}
$$

Concentration:

$$
\frac{d}{d t}\left(, b^{2} c\right)=-r b^{2} k c^{m}+2 a r b^{2} c_{0} \frac{d r}{d t}
$$

where the quantities are as defined in Secdion 5.4, with the addition that $c_{0}$ is the ambient reactant concentration. and $m$ is the order of the reaction, $m=1,2 \ldots$.

Taking a simple Arrhenius reaction rate of the form:

$$
k=A \exp \left(-\frac{E}{R T}\right)
$$

and defining some new parameters as: 
normalized specific exothermicity:

$$
q^{*}=\frac{q c_{0}}{\rho_{0} h_{0}}
$$

characteristic chemical reaction time:

$$
t_{c h}=\frac{1}{A c_{0}^{m-1}} \exp \left(\frac{E}{R T_{0}}\right)
$$

reduced ambient temperature:

$$
\varepsilon=\frac{R T_{0}}{E}
$$

the conservation equations (6.1) to (6.4) can be put into normalized form, with $c^{*}=c / c_{0}$, as:

$$
\begin{aligned}
& \frac{d}{d t^{*}}\left(r^{*} b^{2} \beta\right)=2 \alpha r^{*} b^{*}\left(\frac{d r^{*}}{d t^{*}}\right) \\
& r^{*} b^{\cdot 2} \frac{d r^{*}}{d t^{*}}(\beta+k)=1 \\
& \left.\frac{d}{d t^{*}}\left(r^{*} b^{* 2}(1-\beta)\right)=q^{\cdot}\left(\frac{t_{m}}{t_{c h}}\right) r^{*} b^{* 2} c^{* m} \exp ^{(1-\Lambda \beta} \frac{1-\frac{1}{\varepsilon}}{\varepsilon}\right)
\end{aligned}
$$

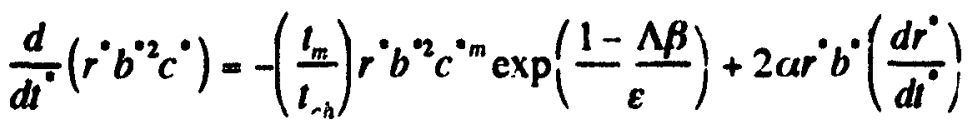

The solution of $(6.6)$ to (6.9) requires careful attention to Initial conditions as well as to the real temperature profle of the element. assumed uniform in the model, due to the exponential function in the Arrhenius term. These detalls are treated in Topham et al. (1986). 
Instead of a numerical exploration of the solutions to (6.6) to (6.9). we anticipate, In analogy with the spherical element case, that the combustion sulution will produce a self-sustaining element which maintalns a near constant densily, corresponding to a high-temperature state. Setting $B$ to $B_{C}$ in (6.1) and (6.2), we c btaln the constant density soluttons (see Appendix III for detalis):

$$
\begin{gathered}
b^{\circ}-\Psi_{c}+\left(1-\Psi_{c}\right) r^{-\frac{1}{2}} \\
\frac{1}{4} \Psi_{c}^{2}\left(r^{* 4}-1\right)+\frac{4}{5} \Psi_{c}\left(1-\Psi_{c}\right)\left(r^{-\frac{5}{2}}-1\right)+\left(1-\Psi_{c}^{2}\right)\left(r^{\cdot}-1\right)-\frac{1}{\beta_{c}+k} i^{\circ}
\end{gathered}
$$

where:

$$
\Psi_{c}=\frac{1}{\beta_{c}} \Psi=\frac{1}{\beta_{c}}\left(\frac{2}{3} \alpha \frac{r_{0}}{b_{0}}\right)
$$

As anticipated, the fully combusting solutions mirror the spherical element case because the effect of heat addition leads to an increase in the entralnment rate by the factor $1 / B_{c}$.

\subsection{Ignition Criteria}

The appearance of two distinct classes of solutions in the spherical element combustion model of Topham et al. (1986) is an important result. Numerical exploration of the equations indicated that the parameter: 


$$
\frac{1}{a} \frac{I_{m}}{I_{c h}}
$$

was critical in determining the kernel behaviour. High values lead to combustion, low values lead to extinction.

For the toroldal element, the same sensitivity to the above tarameter can be seen in equation (6.9). If the fully combusting staie is to be achieved. then the density ratio attains a constant level. $B_{c}$. and the concentration, $c^{*}$, must go from an inittal value of zero to some maximuni. $c^{*}$ max, and then quickly to zero as reactant is consumed within the element. Thus, the time dertvative of the concentration must go through a zero, and using this we can obtain from equation (6.9) the condition:

$$
\frac{1}{\alpha} \frac{t_{m}}{l_{c h}}\left[c_{\operatorname{man}} \exp \left(\frac{1-\Lambda \beta}{\varepsilon}\right)\right] \geq O(1)
$$

Using values of $c^{*} \max$ in the range of $0.05 \cdot 0.10$ and $B_{c}$ in the range of 0.2 - 0.4, which are taken from the numerical solutions of Topham et al. (1986), estimates for the combustion parameter (6.12) can be obtained from (6.13) to determine whether a self-sustalning or extinction solution will occur. Thus, (6.13) can be vlewed as an Ignition criterion for the very early phase of spark ignition. The further development of the kernel from the early phase (where mixing controls the dynamics) to a fully 
developed flame front propagating Into the remaining mixture (where thermal diffusion controls the dynamics) has not been addressed here. This would require perhaps using the mixing model developed here to provide Initial conditions for the more recent thermal modeis of Ko et al. (1991). Th!s is left as future work.

Measurements of real ignition kernels are lacking, so complarison of the toroldal combustion model is not possible yet. However, the comparison of the spherical element model with plasma jet data in combustible mixtures is sufficiently encouraging that we can draw several conclusions from the toroidal molel with some degree of confldence.

First, the value of the combustion parameter (6.12) is critical in determining the evolution of the kernel. Unlike strictly thermal models of ignition, this parameter combines the fluid mechanical properties of the energy, momentum. and vorticity distribution of the kernel, with the properties of the chemical reaction.

Second, for a fixed energy Input, a device which imparts high momentum has a short fluid time scale, $t_{m}$. which inclines the element towards extinction. On the other hand, low momentum is favourable for combustion. Plasma jet devices, for example, can vary the impulse delivered by changing the dimensions of the cavity. Axlal discharges can reduce the delivered Impulse by Increasing the discharge time. In the case of the fast discharge kernels measured by Maly and Vogel (1978) and used In Section 5.5. we speculate that, as the central iemperature rapidly 
fell, the kernels had too high an Impulse to achleve self-sustaining conditions. Hence, the non-combusting model was more approprlate.

Third, glven that high momentum devices are not apparently favourable for ignition, why do plasma jets and fast discharge igniters demonstrate a clear ability to ignite lean mixtures? For a given mixture ratio, say a lean mixture, the critical combustion parameter indicates that the mixing time $t_{m}$ would have to be sufficlently long to achleve the selfsustaining state. Apart from numerical constants, the mixing time $t_{m}$ is essentially the same for both the spherical and toroldai cases and. more importantly, we can write:

$$
t_{m} \propto \frac{H^{\frac{4}{3}}}{I}
$$

Thus, the energy imparted to the kernel is still very impoitant to the establishment of Ignition. Even though plasma jets and fast discharge devices impart a relatively high momentum to the kernel, they also deliver high energy, compared to a conventional axlal discharge or common spark plug. In the case of the plasma jet, the discharge is bounded, except at the orifice, and measurements (Smy et al. 1983) Indicate that about $10 \%$ of the $1-2 \mathrm{~J}$ of the total discharge circult energy is Imparted to the kernel. This is true when the discharge time is on the order of twice the time it takes an acoustic wave to travel the length of the cavity and the radial expansion of the arc has just contacted the cavity walls. 
This latter condition arises from the bounded nature of the discharge. The hot gases are expelled from the cavity on the order of the acoustic travel time and. If the arc contacts the cavity walls, high energy losses occur. Thus, discharges lasting longer than the time it takes to expel the cavity, or long enough to contact the cavity walls, waste the discharge energy.

In the case of fast discharge devices, where the discharge is open or unbounded, it is the low Inductance of the discharge circuit that promotes the coupling of the avallable energy, typically $10.30 \mathrm{~mJ}$, to the kernel. Circults that discharge their energy in $100-500 \mathrm{~ns}$ are delivering it to a circult element, the spark gap, whose impedance more nearly matches the rest of the circult. This impedance match only lasts a short time, as discussed in Chapter 2. Thus, plasma jet and fast discharge devices coup' much higher energles to their spark kcrnels than do conventional igniters which typically deliver $1-2 \mathrm{~mJ}$ to their Ignition kernels. This makes the former more effective igniters in lean mixtures.

\subsection{Ignition in Turbulent Mixtures}

Ignit!on in most practlical systems takes place against a background of amblent turbulence. Given that igrittion kernels are now to be viewed as regions of concentrated vorticity, their interaction with a general background of turbulence would be valuable knowledge. The following 
discussion is treated in more detall in the paper by Pitt et al. 1991. which appears in Appendix I.

Our observations of spark kernels from axial discharges Indicate that the kernels start out as coherent toroldal structures and then an Instability occurs which causes a transition to a more rapid, turbulent mixing state. This can be seen in the Schlleren photographs of Section 4.4. We propose that the intrinsic mixing properties of the element itself dominate its evolution for a significant period and that the role of ambient turbulence is to control the transition of the element to the more turbulent state. For given discharge conditions, the more intense the amblent turbulence, the earlier transition occurs and the greater the proportion of the total momentum incorporated directly into the now turbulent kernel. As the mixing rate of the kernel is proportional to the Inverse of the momentum, higher amblent turbulence leads to more rapid evolution of the kernel. A comparison between the mixing model and published results on the spreading kernels in turbulent mixtures lends some support to this view (Pitt et al. 1991).

The spark kernel model presented in the previous chapter, and further developed in this chapter to include the effects of combustion, represents a primitive state of knowledgc. The reason is the lack of suitable data which accurately ...easure the energy and momentum of kernels or the temporal progress of the major and minor radil. Such measurements are experimentally challeriging. The model more closely resembles the observed kernel structures and, for the first time, links the types of 
83

structures produced by common electrical discharge igniters to the same underlying physical process. The traditional view of an ignition kernel as a point heat source whose evolution is governed by diffusive processes overlooks the essential mechanism of fluld dynamics which dominate Immediately following the initial shock wave and persist until a freely propagating flame is established. Consequently, the traditional view falls to predict the observed kernel structures and the critical processes Involved. 
This thesis presented a new view of spark Ignition that links all electrical discharge ignition devices through a common physical mechanism-hydrodynamic mixing. Our viewpolnt manifested Itself In the following way.

We began by establishing the motivation for lean-burn or alternative fueled IC engines. Reduced emissions and fuel efficlency are the dual goals behind this move. Ignition difficulties arise. however, when the operating point of an engine is moved to leaner conditions or an alternative fuel such as natural gas is substituted for gasoline. We demonstrated, in Chapter 2. some practical means by which the Ignition delay, an annoying problem of lean mixtures, can be reduced. Results from qulescent combustion bomb experiments and IC engines led us to conclude that, aside from demonstrating the reduction of Ignition delay. Ignition devices affect onlj' the early phase of ignition in IC engines. The bulk turbulence in an engine combustion chamber dominates the overall combustion event. Effects seen in quiescent combustion vessels disappear in real engines, except for the 1-2 ms beginning phase of the event.

With the early phase of spark Ignition established as the critical period at which ignition devices can influence IC engines, the focus of the thesis shifted to a discussion of the conventional thermal thiory of Ignition -a theoretical framework that has shaped most of the 
theoretical, experimental, and practical thinking on ignition for nearly 50 years. The thermal approach to spark Ignition vlews the spark discharge as a point or line heat source that ralses a critical volume of mixture to the flame temperature. Heat loss, by conduction, to the surrounding mixture is the critical mechanism that determines the minimium spark energy for ignition. Furthermore, the thermal approach predicts that the ignition kernel would develop as a spherically symmetric reglon pocessing an exponentially decaying radial temperature proflle. This prediction was challenged by experimental observations, some new and others from existing IIterature, which clearly showed that spark kernels from axial dis_harges initially develop as sharply bounded, toroidal regions of hot gas.

We discussed the importance of the temporal characteristics of the electrical discharge. Energy dellvered to the spark gap in the first 10.6 $\mathbf{s}$ was seen to drive the spiurk kernel's behaviour. The energy delivered at later times is less effective in feeding the spark kernel. as more of the discharge energy is going Into supporting the arc phase of the discharge. which suffers heavy energy losses, mostly to the electrodes. Thus, conventional automotive engineering wisdom of long, typically 1-10 ms discharges is not well founded.

In Chapter 5, we stood back and looked at the evidence of Chapter 4 and argued that the toroldal structures produced by axdal discharges are a result of underlying hydrodynamic clrculation patterns which 
are strikingly similar to flows in plasma jet spark kernels. Armed with this insight, we proposed a classiffcation scheme that links the practical Ignition sources of Chapter 2 to a fundamental process: hydrodynamic mixdng. This classification scheme sees plasma jet. puff Jet, and surface discharge Ignition devices producing spark kernels with spherically symmetric circulation patterns and structures. Axdal discharges produce toroldially symmetric circulation patterns and structures.

A mixdng model, developed by Topham et al. (1084) for interpreting plasma jet spark kernel behaviour, was modifled to the toroldal geometry of axial discharge spark kernels. The mixing model required knowledge of the momentum Imparted to the developing spark kernel. Such measurements are rare since the dominant theoretical framework Ignored the kernel's Impulse and subsequent flows. However, we were able to make an initial comparison of some limited data with the mixing model. The results are encouraging, but must be interpreted cautiously because of the limited data set avallable. Obviously, further measurements are required before more definite claims can be made.

In Chapter 6, our mixing model was extended to the realm of combustible mixtures following the experience of the spherical element solutions developed for plasma jet kernels (Topham et al. 1986) A distinct combusting solution was sought which featured a constant, below-amblent level element density, reflecting a high- 
temperature, self-susialning state. An Ignition criterion was discussed which identifled a common combustion parameter:

$$
\frac{1}{a} \frac{t_{m}}{t_{c n}}
$$

This parameter comblnes the energy, momentum, and resulting vorticity distribution of the kernel. together with the exothermic propertles of the mixture. The combustion parameter is the essence of the mixing models discussed, because it identifies the balance between heat release and hydrodynamic mixing as the controlling mechanism in the early phase of ignition by electrical discharges. The Ignition system designer is then encouraged to take into account the role of the momentum imparted to the spark kernel, which manifests Itself through the mixing time $t_{m}$. since:

$$
\tau_{m} \propto \frac{H^{\frac{4}{3}}}{T}
$$

For a given energy, low momentum devices produce kernels that are more effective for Ignition in very lean mixtures.

Chapter 6 concludes with a reinterpretation of measurements of spark kernels in turbulent combustible mixtures, using the mixing model as a guide. It is proposed that the observed transition of toroldal elcment's from coherent to fully turbulent structures is affected by amblant turbulence. The greater the turbulent Intensity, the earller 
the transition occurs, the greater the proportion of total momentum Incorporated directly Into the now more turbulent element, and the faster the inixing time. A comparison between the model and published data on the spreading rate of kernels in turbulent mixtures lends some support to this vlew.

\section{Serendipity}

We cannot end without mentioning the striking similarity between the photographs of toroldal spark kernels and the photographs of several planetary nebulae. For example, photographs of the RIng Nebulae, M 57, the Helix Nebulae. NGC 2244, and many other astronomical objects show similar, well-defined toroldal structure. but on vastly larger scale than the spark kernels discussed in Chapter 4. We wonder, if we modify the mixing model. . .

Everything of importance has been sald before by somebody who did not discover it.-A. N. Whitehead 
Literature cited

Aldeman H.G. (1981) Eighteenth Symp Int'] on Combustion. The Combustion Institute, p 1333.

Akınciele, O. O., D. 5radley, P.W. Mak and M. Mcmahon (1982) Combitstion and Flame, 47, 129

Agnew (1984) Twentieth Symp Int'l on Combustion, The Combustion Institute, p 1

Ballai' D.R., A. H. Lefebvre (1975) Comb. and Flame, 24 99

Ballal D.R., A. H. Lefebvre (1977) Proc. Roy. Soc. Lond., A357, 163.

Ballal D.R., A. H. Lefebvre (1981) Eighteenth Symp Int'l on Combustion. The Combustion Institute, p 1737

Bradley, D. and I.L. Critchly (1974) Comb. and Flame, 22, 143.

Borghese, A., A. D'Alessio, M. Diana, and C. VenitozzI. (1988) Twentysecond Symp. Int'l on Combustion, The Combustion Institute. p. 1651.

Calcote H. F., C.A. Gregory, C.M. Barnett, F..B. Gilmer( 1952) Ind. Eng Chem.44, p. 2656

Chomiak J.(1979) Seventeenth Symp Int'l on Combustion. The Combustion Institute, p. 255

Clements (1984) The Chemistry of Combustion Processes, T.M. Sloan ed. A.C.S, p. 193.

De Sote G. G.(1971) Thirteenth Symp Int'l on Combustion. The Combustion Institute, $\mathbf{p} 735$

Dixon -Lewls G.,I.G. Shepherd (1975) Fifteenth Symp int'l on Combustion. The Combustion Instliute, p

Fisher P.D., P. L. Pitt, J.D. Ridley, R. M. Clements (1986) Comb. Scl. and Tech. 46, 137

Frank - Kanemetskil D. A. (1947) Diffusion and Heat Exchange in Chemical Kinetics, Princeton Univ. Press.

Hadley, R.F. and P.R. Smy (1989) J. Phys. D: Appl. Phys. , 22, 258.

Kono M., S. Kuagal, T. Sakal, Combustion and Flame, 27, 85.(1976) 
Kono, M.S., K. Niu, T. Tsukamoto, and Y. Ujle, (1988) Twenty-second Symp. Int'l on Combustion. The Corisbustion Institute, p. 1643.

Kuffel, E. and W. S. Zaengl (1984) High Voltage Englneerling. Permagon Press.

Lewts B., G. von Elbe (1961) Combustion, Flames and Explosions of Gases, Academic Press

Linett .J.W. (1952) Selected Problems In Combustion, vol II. Butterworth . p. 139

Mallard E. , H. Chatallier (1881) C.R. Acat Sct Parts, 93, 145.

Maly R. (1981) Eighteenth Symp Int'l on Combustion. The Combustion Institute, p 1747

Maly R., M. Vogei (1977) Seventeenth Symp int'l on Combustion. The Combustion Institute, p 821

Morton B. R. , G. I. Taylor and J. S. Turner (1956) Proc. Roy. Soc. Lond. A234, 1.

Oppenhelm. A. K. (1985) Phil. Trans. R. Soc. Lond. A 315. 471

Oran E. S. . J.P. Borts (1982) Combustion in Reactive Systems Bowen et al eds. vol 76, Piogress in Astronautics and Aeronautics AIAA. New York. 154

Orrin. J.E., !.M. Vince ana F.J. Weinberg (1981) Eighteenth Symp Int'l on Combustion. The Combustion Institute. p 1755

Olsen H. L., R. B. Edmonson, and E. L. Gayhart (1952) J. Appl. Phys. 23, 1157.

Pitt P.i.. R. M. Clements (1933) Comb. Scl. and Tesh. 30, 327

Pitt P.I.. J.D. Riciley, R. M. Clements (1984) Cimb. Scl. and Tech. 35. $27 ?$

Pitt P.L.. J.D. Ridley, R. M. Clements (1985) Comb. Sci. and Tech. 38. 217

Pitt, P.L.. Clements, R.M., Topham, D.R. 1991. The Early Phase of Spark Igrittion. Comb. Scl. and Tech. 78, F 289.

Rafeal S., E. Sher (1985) Comb. and Flame, 59, 17. 
P.jdley J.D., P. L. Pitt., R. M. Clements ( 1985 ; Comb. Scl. and Tech. 43. 39

Solomon, A.S. P.,(1988) SAE Paper 88025

Smy, P.R., R.M. Clements, J.D.Dale, D. SimeonI, and D.R. Topham. (1983) J. Phys D: Appl Phys., 16.783.

Semenov N.N. (1935) Chemical Kenetics and Chaln Reacions, $O x$. Univ. Press.

Swett C. C. (1952) Sixth Symp Int'l on Combustion. The Combustion Institute, p 523.

Topham D.R., J. X. Zhang. K M. Clements and P. R. Smy (1982) J. Phys. D:Appl Phys.15. L65

Topham D.R.. R.M. Clements and P. R. Smy (1975) Comb. and Flame, 25, 187

Topham D.R., R.M. Clements and P. R. Smy (1984) J. Fluld Mech., 148. 207

Topham D.R.. J. D. Ridley, R.M. Clements and P. R. Smy (1986) Comb. Scl, and Tech., 50, 41

Turner J. S. (1986) J. Fluld Mech., 178, 431.

Welnberg, F.J., K. Hom. A.K. Oppenhelm, and K. Teichman (1978) Nature. 272, 341

Zeidovich, Y.B., D.A Franis-Kamenetsklı, and N.N. Semenov.(1940) J. Exp. Theor. Phys., 10, 1427

Zlegler G.F.W. E.P. Wagner, and R. Maly (1984) Twentieth Symp Int'I on Combustion. The Combustion Institute, p 1871. 


\section{Appendix I Papers published by the author}

The University Llbrartan has recommended that published papers which I have co-authored not be reproduced in this appendix out of respect for copywright protection laws. I therefore present references to specific papers so that an interested reader can pursue them.

Work on plasma jet Ignition in natural gas fueled engines can be found in:

Pitt P.L. R. M. Clements (1983) Comb. Scl. and Tech. 30. 327

Work on the development of the puff-jet ignition concept can be found In:

Pitt P.L.. J.D. Rudley, R. M. Clements (1984) Comb. Scl. and Tech. 35. 277

Pitt P.L.. J.D. Ridley, R. M. Clements (1985) Comb. Sct. and Tech. 38. 217

Ridiey J.D., P. L. Pitt., R. M. Clements (1385) Comb. Scl. and Tech. 48. 39

Fisher P.D., P. L. Pitt, J.D. Ridley. R. M. Clements (1986) Comb. Scl. and Tech. 46, 137

Work on the toroldal mixing model of spark ignition can be found in:

Pitt, P.L.. Clenients, R.M., Topham. D.R. (i991). The Early Thase of Spark Ignition. Comb. Scl. and Tech. 78, p. 289. 
The scaled conservation equations developed in Chispter 5 are repeated here:

$$
\begin{aligned}
& \frac{d}{d t^{*}}\left(\beta r^{0} b^{\cdot 2}\right)=2 a \frac{r_{0}}{b_{0}} r^{\circ} b^{\circ} \frac{a^{0} i^{0}}{d t^{\circ}} \\
& r^{\circ} b^{-2}(\beta+k) \frac{d r^{0}}{a^{0}}=1 \\
& r^{\circ} b^{*}(1-\beta)=1
\end{aligned}
$$

To obtain an expression for $b^{*}$ in terms of $r^{*}$, the calculation proceeds as follows. Equeting (A2) and (A3), we obtaln

$$
\frac{d r^{\circ}}{d t^{\circ}}=\frac{1-\beta}{\beta+k}
$$

Rewriting (A3) as

$$
\dot{r} b^{2}=\frac{1}{1-\beta}
$$

and using this, the LHS of Al becomes

$$
\frac{d}{d t^{0}}\left(\beta r^{0} b^{2}\right)-\frac{d}{d t^{0}}\left(\frac{\beta}{1-\beta}\right)=\frac{d}{d t^{2}} x
$$

where 


$$
x=\frac{\beta}{1-\beta}
$$

The RHS of (AI) 1s, using (A4) and (A5),

$$
2 a \frac{r_{0}}{b_{0}} r^{\circ} b^{0} \frac{d r^{\circ}}{d t^{\circ}}=2 a \frac{r_{0}}{b_{0}} \frac{1}{b^{\circ}} \frac{1}{\beta+k}
$$

Thus (Al) can be put Into the following form:

$$
\frac{d x}{d t^{b}}=2 \alpha \frac{r_{0}}{b_{0}} \frac{1}{b} \frac{1}{\beta+k}
$$

Again. using (A3), we can express b* as

$$
b^{0}=\left(\frac{1}{r} \frac{1}{1-\beta}\right)^{\frac{1}{2}}
$$

Using this result in (A6), we obtain

$$
\frac{d \chi}{d l^{9}}=2 \alpha \frac{r_{0}}{b_{0}}+\frac{1}{2} \frac{(1-\beta)^{\frac{1}{2}}}{\beta+k}=2 \alpha \frac{r_{0}}{b_{0}}+\frac{-\frac{1}{2}}{(1+k) \chi+k}
$$

Equation (A2) can be re-written as

$$
\frac{d r^{0}}{d t^{0}}-\frac{1}{(1+k) x+k}
$$


Using (A6) and (A8), an expresslon for $\frac{d r^{\circ}}{d x}$ can be calculated:

$$
\frac{d r^{0}}{d x}=\frac{a r^{0} / d t^{0}}{d x / d t^{0}}-\frac{1}{2 \alpha \frac{r_{0}}{b_{0}} r^{\frac{1}{2}}(1+x)^{\frac{1}{2}}}
$$

Equation (A9) can be integrated, using the Initial conditions listed in Tabie 5.3

$$
2 a \frac{r_{0}}{b_{0}} \int_{1}^{0^{0}} r^{\frac{1}{2}} d r=\int_{0}^{x} \frac{d \chi^{\prime}}{\left(1+x^{\prime}\right)^{\frac{1}{2}}}
$$

Using $1+\chi=\frac{1}{1-\beta}$, the results of the Integration can be rearranged to yleld

$$
b^{\cdot}=\frac{2}{3} a \frac{r_{0}}{b_{0}} r^{\cdot}+\left(1-\frac{2}{3} a \frac{r_{0}}{b_{0}}\right) r^{--\frac{1}{2}}
$$

Setting $\Psi=\frac{2}{3} a \frac{r_{b}}{b_{0}}$, then $\left(a_{i} i 0\right)$ can be put into the form used in Chapter 5 as equation (5.14):

$$
b^{0}-\Psi_{r}+(1-\Psi) r \cdot \frac{1}{2}
$$

To calculate $r^{*}\left(t^{*}\right)$, we integrate (A8) after computing $\chi\left(r^{*}\right)$. Using (A4) and (A5), we obtain 


$$
\frac{a r^{0}}{d t^{0}}=\frac{1}{r b^{2}} \frac{1}{\beta+k}
$$

From (A6) we have

$$
\frac{1}{\beta+k}=\frac{b^{0}}{2 a \frac{r_{0}}{b_{0}}} \frac{d x}{d t}
$$

Sustituting (A12) Into (AI1) ylelds

$$
\frac{d x}{d r}=2 a \frac{r_{0}}{b_{0}} \cdot b^{\circ}
$$

which can be integrated, using (5.3), resulting in

$$
x=\Psi^{2}\left(r^{3}-1\right)+2 \Psi(1-\Psi)\left(r^{-\frac{3}{2}}-1\right)
$$

Substituting (5.15) Into (A8) produces an equation which can be Integrated directly to yteld equation (5.16) of Chapter 5

$$
i-\left(\frac{1+k}{4}\right) \Psi^{2}\left(r^{\cdot 4}-1 j+\frac{4}{5}(1+k) \Psi(1-\Psi)\left(r^{\cdot \frac{3}{2}}-1\right)+\left\{k-(1+k)\left[2 \Psi-\Psi^{2}\right]\right\}\left(r^{\cdot} \cdot-1\right)\right.
$$

which completes the solution of the non-combusting model. 


\section{Appendix III Constant Density Solutions}

For these solutions, we set $\beta \rightarrow \beta_{c}$, where

$$
\beta_{c}=\text { constant density ratio. }
$$

In (A1) and (A2) of Appendix II. The constant density modiel in thus described by

$$
\begin{aligned}
& \beta_{c} \frac{d}{d t^{0}}\left(r^{\circ} b^{n}\right)=2 a \frac{r_{0}}{b_{0}} \dot{r}^{\circ} b^{\circ} \frac{d r^{\circ}}{d t^{\circ}} \\
& \dot{r}^{\circ 2}\left(\beta_{c}+k\right) \frac{d r^{\circ}}{d t^{\circ}}=1
\end{aligned}
$$

Expanding the l.HS oi (BI) and collecting terms ytelds

$$
\frac{d b^{\circ}}{d r^{\circ}}-\frac{a}{\beta_{c}} \frac{r_{0}}{b_{0}}-\frac{b^{\circ}}{2 r^{\circ}}
$$

If we assume that a solution for (B3) has a functional form stmilar to the non-cumbusting case, then

$$
b^{0}=a_{1} r^{0}+a_{2} r^{--\frac{1}{2}}
$$

where $a_{1}$ and $a_{2}$ are undetermined coefficlents. Substituting (B4) into (B1) and comparing terms ylelds 


$$
a_{1}=\frac{2}{3} \frac{\alpha}{\beta_{e}} \frac{r_{0}}{b_{0}}
$$

From the Initial conditons $\left(b^{*}=1\right.$ when $\left.r^{*}=1\right)$, equation $(B 4)$ glves

$$
1=a_{1}+a_{2}
$$

Therefore

$$
a_{2}=1-\frac{2}{3} \frac{a}{\beta_{c}} \frac{r_{0}}{b_{0}}
$$

and (B4) besomes

$$
\begin{gathered}
b^{0}=\frac{2}{3} \frac{\alpha}{\beta_{c}} \frac{r_{c}}{b_{0}} r^{\cdot}+\left(1-\frac{2}{3} \frac{\alpha}{\beta_{c}} \frac{r_{0}}{b_{0}}\right) r^{-\frac{1}{2}} \\
-\Psi_{c} r^{+}+\left(1-\Psi_{c}\right) r^{-\frac{1}{2}}
\end{gathered}
$$

where

$$
\Psi_{c}=\frac{2}{3} \frac{a}{\beta_{c}} \frac{r_{0}}{b_{0}}=\frac{1}{\beta_{c}} \Psi
$$

Equation (B5) resembles the non-combusting solution with $a$ replaced by $\alpha / \beta_{c}$. To complete the solution, we solve (32), using (B5). Thus (B2) becomes 


$$
\frac{d r^{0}}{d t^{\varphi}}=\frac{1}{\beta_{s}+k} \frac{1}{\Psi_{c}^{2} r^{\cdot 3}+2 \Psi_{c}\left(1-\Psi_{c}\right) r^{-\frac{3}{2}}+\left(1-\Psi_{c}\right)^{2}}
$$

which can be integra.ed directly to give

$$
\frac{1}{4} \Psi_{c}^{2}\left(r^{* 4}-1\right)+\frac{4}{5} \dot{\psi}_{c}\left(1-\Psi_{c}\right)\left(r^{\frac{5}{2}}-1\right)+\left(1-\Psi_{c}^{2}\right)\left(r^{\cdot}-1\right)-\frac{1}{\beta_{c}+k} i(B 6)
$$

